\title{
Integrating Content and Process Models to Study Turnover in the Canadian Forces
}

\author{
by \\ Jeffery Wayne Gauger \\ B.A., Hons, University of New Brunswick, 2001
}

A thesis submitted to the Faculty of Graduate and Postdoctoral Affairs in partial fulfillment of the requirements for the degree of

Master of Arts

in

Psychology

Carleton University

Ottawa, Ontario

(C) 2013, Jeffery Wayne Gauger 
Library and Archives

Canada

Published Heritage

Branch

395 Wellington Street

Ottawa ON K1A ON4

Canada
Bibliothèque et

Archives Canada

Direction du

Patrimoine de l'édition

395 , rue Wellington

Ottawa ON K1A ON4

Canada
Your file Votre référence

ISBN: 978-0-494-94299-4

Our file Notre référence

ISBN: 978-0-494-94299-4
NOTICE:

The author has granted a nonexclusive license allowing Library and Archives Canada to reproduce, publish, archive, preserve, conserve, communicate to the public by telecommunication or on the Internet, loan, distrbute and sell theses worldwide, for commercial or noncommercial purposes, in microform, paper, electronic and/or any other formats.

The author retains copyright ownership and moral rights in this thesis. Neither the thesis nor substantial extracts from it may be printed or otherwise reproduced without the author's permission.
AVIS:

L'auteur a accordé une licence non exclusive permettant à la Bibliothèque et Archives Canada de reproduire, publier, archiver, sauvegarder, conserver, transmettre au public par télécommunication ou par l'Internet, prêter, distribuer et vendre des thèses partout dans le monde, à des fins commerciales ou autres, sur support microforme, papier, électronique et/ou autres formats.

L'auteur conserve la propriété du droit d'auteur et des droits moraux qui protege cette thèse. $\mathrm{Ni}$ la thèse ni des extraits substantiels de celle-ci ne doivent être imprimés ou autrement reproduits sans son autorisation.
In compliance with the Canadian Privacy Act some supporting forms may have been removed from this thesis.

While these forms may be included in the document page count, their removal does not represent any loss of content from the thesis.
Conformément à la loi canadienne sur la protection de la vie privée, quelques formulaires secondaires ont été enlevés de cette thèse.

Bien que ces formulaires aient inclus dans la pagination, il n'y aura aucun contenu manquant. 


\begin{abstract}
Content models of voluntary employee turnover explore why people quit organizations; while process models explore how they quit. The present research integrated content and process models to explore if why military members quit was related to how they quit. A thematic analysis of quit decisions was conducted along with an analysis of the decision path, in terms of time it took to make the quit decision and how difficult it was to make it. Results suggest that $50 \%$ of personnel quit as a result of a shock with the most frequent internal shocks being related to postings (transfers), and the most frequent external ones related to family matters. Significant differences for length and difficulty of quit decision were also found. The findings of this study contribute to the existing content - process integration in the turnover research and to the understanding of the quit decision process in a military organization.
\end{abstract}




\section{Acknowledgements}

Without the love and support of my beautiful wife Sandra, I would never have achieved this goal, for that, I will be forever thankful, I Love you! I would like to thank my cosupervisors, Dr. Tzvetanka Dobreva-Martinova and Dr. Janet Mantler for the countless hours, knowledge and guidance they contributed throughout this process. I would also like to thank my committee members, Dr. Connie Kristiansen, Dr. Don McCreary and Dr. Steven Murphy for their participation and help throughout. Lastly, I would like to thank the leaders in the Canadian Forces for their belief in higher education. 


\section{Table of Contents}

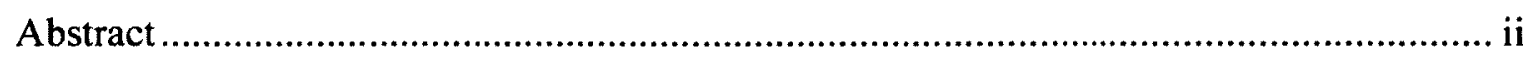

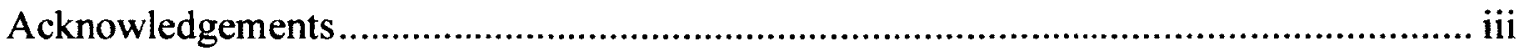

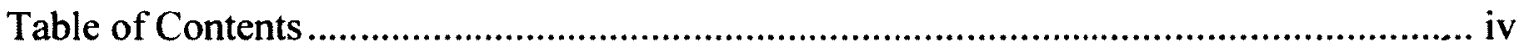

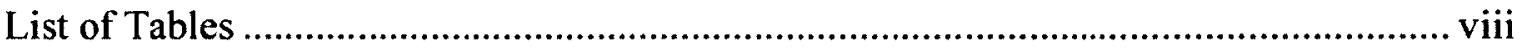

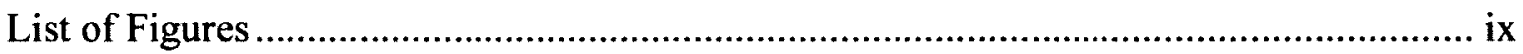

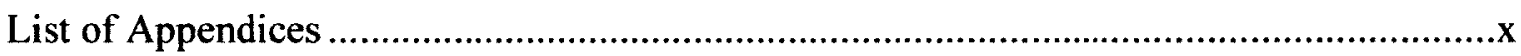

Integrating Content and Process Models to Study Turnover in the Canadian Forces .........1

Understanding Turnover............................................................... 4

The Why and the How of Voluntary Turnover ......................................... 5

Content Models of Voluntary Turnover - Why ..................................... 6

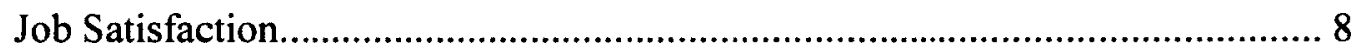

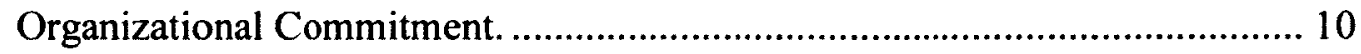

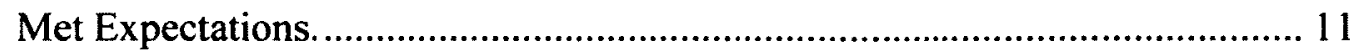

Process Models of Turnover - How .................................................. 13

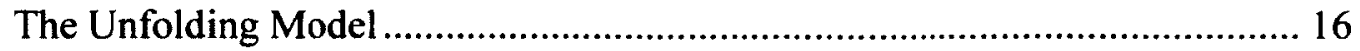

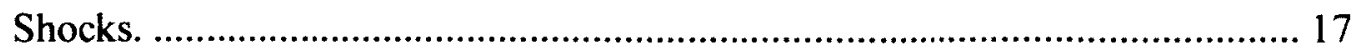




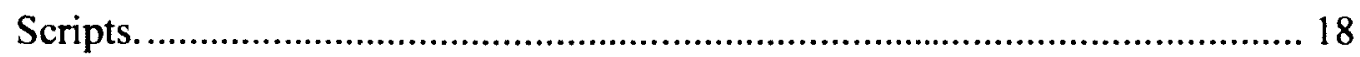

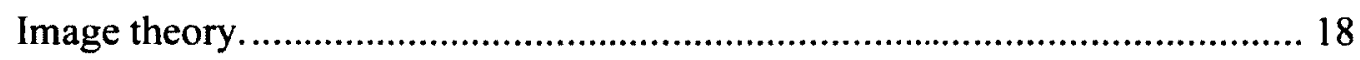

The Unfolding Model - Decision Paths...................................................... 21

Job alternatives.

Job offer as a shock.

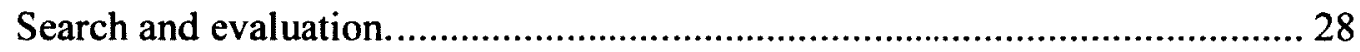

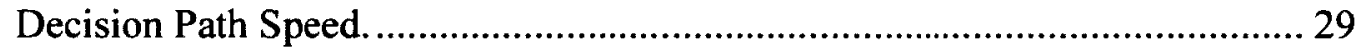

An Integration of Process and Content Models................................................ 30

Voluntary Turnover in the Military .................................................................. 32

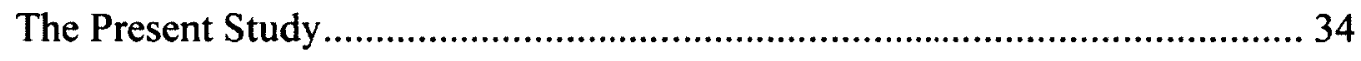

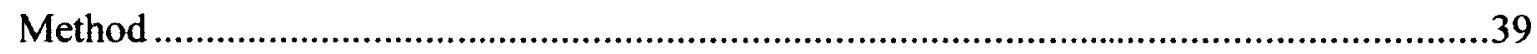

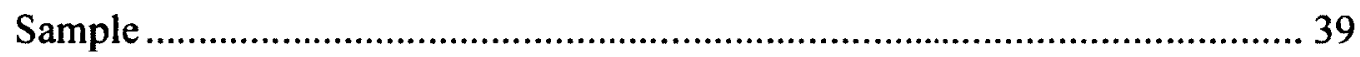

Procedure

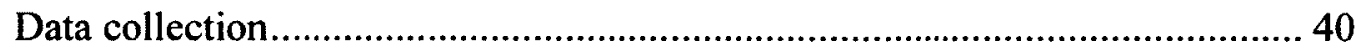

Canadian Forces Exit Survey ........................................................................ 41

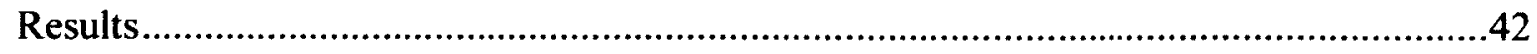

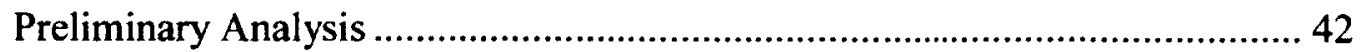




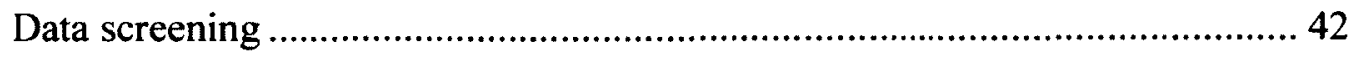

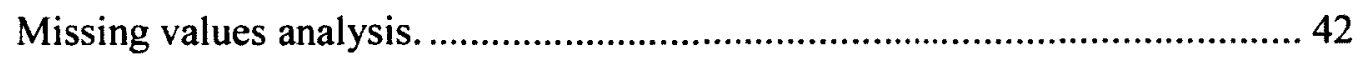

Outliers.

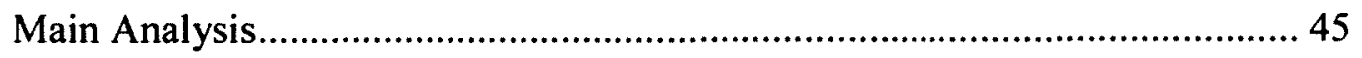

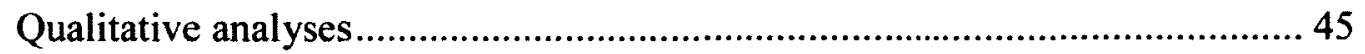

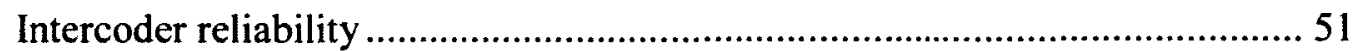

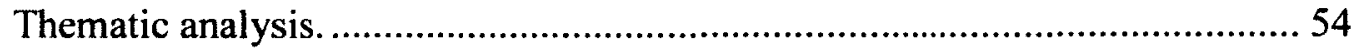

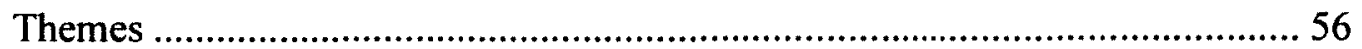

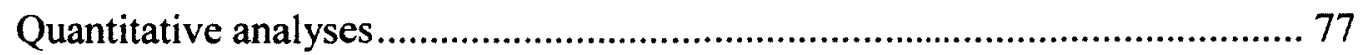

Officers/Non-commissioned members........................................................... 79

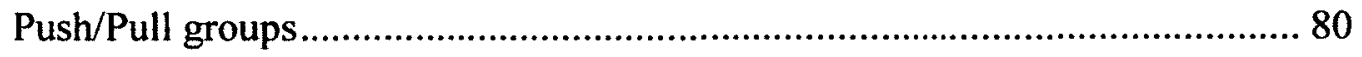

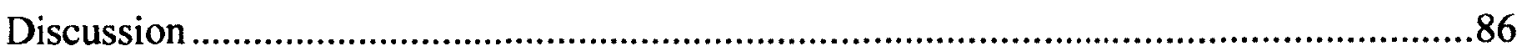

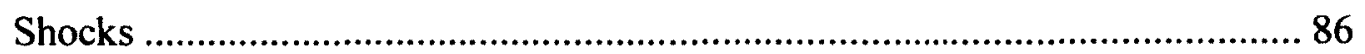

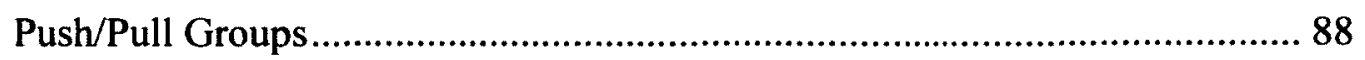

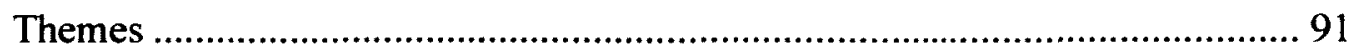

Officers/Non-Commissioned Members ........................................................... 94

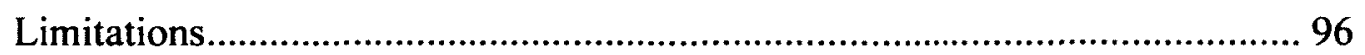




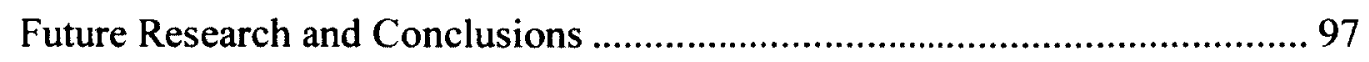

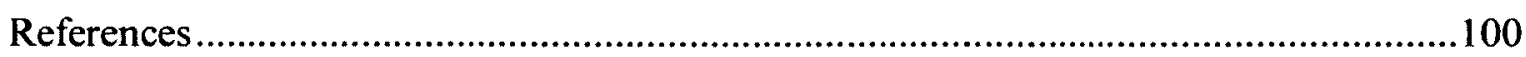

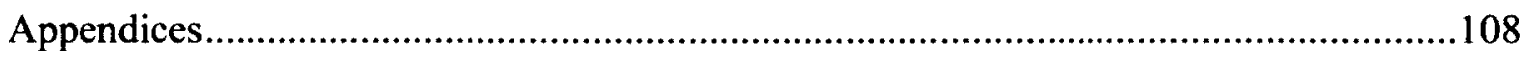

Appendix A: Questions from the Canadian Forces Exit Survey 2008 .......... 108

Appendix B: Responses to "What first prompted you to think about leaving the CF?" - Complete set of themes identified.......................................... 110

Appendix C: Responses to "What finally made you decide to leave the CF?"-

Complete set of themes identified .................................................. 112 


\section{List of Tables}

Table 1. Values of Cohen's Kappa for shock/non-shock,initial thoughts push/pull, final decision push/pull, initial thoughts themes and final decision themes ........................... 54

Table 2. Shock/non-shock, push/pull factor frequence and percent of sample ............... 56

Table 3. Group size, mean rankings for shock and non-shock push/pull groups for

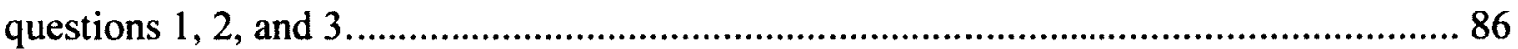




\section{List of Figures}

Figure 1. The Unfolding Model of Voluntary Turnover. An asterisk $\left({ }^{*}\right)$ indicates that the route is not classifiable and that it represents a theory falsification-a way in which an individual could leave an organization that would not be part of one of the model's

paths.

Figure 3. Thematic map of the overall quitting sequence.

Figure 4. Shock - push/pull group frequencies responses to the questions "What first prompted you to think about leaving the CF?" and "What finally made you decide to leave the CF?". 82

Figure 5. Non-Shock - push/pull group frequencies responses to the questions "What first prompted you to think about leaving the CF?" and "What finally made you decide to leave the CF?". 


\section{List of Appendices}

Appendix A: Questions from the Canadian Forces Exit Survey $2008 \ldots \ldots \ldots \ldots \ldots \ldots 108$ Appendix B: Responses to "What first prompted you to think about leaving the CF?"-

Complete set of themes identified...............................................110 Appendix C: Responses to "What finally made you decide to leave the CF?" - Complete set of themes identified.............................................................. 112 


\section{Integrating Content and Process Models to Study Turnover in the Canadian Forces}

Employee turnover is costly to organizations, however, a true estimate of the actual costs of employee turnover is difficult to quantify. Holtom, Mitchell, Lee, and Eberly (2008) noted that organizations do not maintain profit and loss statements that capture the cost of voluntary turnover. A quick search of human resource sites on the internet revealed an abundance of estimates, ranging from $25 \%$ to $200 \%$ of the quitting person's salary. Estimates of the cost of employee turnover fluctuate by job content and industry. Low level, low complexity jobs in high turnover industries, such as food services would require considerably less cost to replace employees than it would cost to replace employees in high skilled industries or professional or managerial positions. Hinkin and Tracey (2006) estimated the cost of replacing a hotel front-desk employee at $30 \%$ of the employee's annual salary. Costs to the organization extend beyond purely monetary measures to include both monetary and non-monetary costs. These costs may be obvious or they may be hidden. Recruiting and training costs can be very expensive. Loss of corporate knowledge and loss of experience and leadership can have a large impact on organizational effectiveness.

Similar to civilian companies, the Canadian Forces are not exempt from the high costs of employee turnover. With an abundance of highly skilled positions and the added costs of teaching all recruits a wide array of military skills, reducing voluntary employee turnover in the Canadian Forces is important. The high costs associated with employee 
turnover are likely a primary reason why employee turnover has been and continues to be so widely studied.

Employee turnover has been extensively researched over the past 50 years. Holtom et al. (2008) estimate that over 1,500 academic articles have been published on the topic, including comprehensive literature reviews by Maertz and Campion (1998), Holtom et al. (2008), and Hom (2011), and meta-analyses by Cotton and Tuttle (1986), Griffeth, Hom, and Gaertner (2000), Hom and Griffeth (1995) and McEvoy and Caisico (1985). Content models have been developed to explain why employees quit their jobs, whereas process models have been developed to explain how employees arrive at their decision to quit their jobs. However, traditional employee turnover models (content models) have been criticized for their low predictive validity, rarely explaining more than $25 \%$ of the variance in actual turnover (Maertz \& Campion, 1998). Moreover, even the most researched antecedents of turnover have demonstrated weak predictive strength (Griffeth et al., 2000), such as estimated effect sizes for organizational commitment $(r=$ $.27)$, overall job satisfaction $(r=-.22)$ and search intentions $(r=.34)$. Weak correlations between turnover antecedents and turnover, and limited predictive validity provided through content models prompted greater emphasis on the withdrawal process that leads to voluntary employee turnover.

Process models attempted to understand the process that employees took prior to leaving their organizations. Mobley's (1977) "intermediate linkages model" was one of 
the first process models introduced and served as a template for the development of subsequent process models. Mobley's model looked past the relation between job satisfaction and turnover by introducing additional factors that can influence a person's decision to quit. However, the still limited predictive ability of the process model research and its reliance on attitudinal measures prompted Lee and Mitchell $(1991,1994)$ to propose a new model of voluntary turnover known as the "unfolding model". Lee and Mitchell $(1991,1994)$ noted that traditional models of voluntary turnover typically assumed turnover decisions consisted of rational thought and involved an evaluative process where job alternatives were considered. The unfolding model provides four decision paths and recognizes that the decision to quit can be spontaneous and without considerable deliberation even when employees are satisfied with their jobs.

Although there was some overlap between content and process models, Maertz and Campion (2004) recognized that no research had been conducted integrating why and how employees quit their organizations. Maertz and Campion (2004) incorporated Lee and Mitchell's (1994) unfolding model into their exploration of how different quitting motives might be systematically related to the quitting process. They hypothesized that different motives (why) would result in specific quit decision paths (how). Maertz and Campion (2004) demonstrated that content-process models could be formally integrated to further theoretical development. Although Maertz and Campion (2004) empirically demonstrated that different turnover motives are systematically related to specific 
decision paths, few studies have used their integration approach, and only one study was found that used a military sample (Holt, Rehg, \& Miller, 2007). To follow up on Maertz and Campion's (2004) study, Holt, Rehg and Miller (2007) used Lee and Mitchell's (1994) unfolding model as a framework to explore the quitting process and to explore the factors (motives) related to the decision to leave an organization using a sample of U.S. Air Force officers. Prior to discussing the integration of the content and process models, voluntary turnover is defined and existing research of content and process models is summarized.

\section{Understanding Turnover}

Maertz and Campion (1998) define voluntary turnover as "instances wherein management agrees that the employee had the physical opportunity to continue employment with the company, at the time of termination" (p. 50). The definition implies that employees make individual choices to leave the organization, but, should they have not chosen to do so, they could have continued employment with the organization (assuming there were no impending medical issues or forced reasons to leave). Further, Hom (2011) indicated that voluntary turnover is the volitional act of leaving the organization permanently and does not involve changes of career fields or locations within the organization.

Turnover is a multidimensional construct that has often been described as having a number of dichotomous dimensions. Of specific concern to employers is the distinction 
between involuntary versus voluntary turnover. Involuntary turnover is typically represented by employer-initiated actions such as dismissals or layoffs; therefore, it is seen as within the organization's control. Involuntary turnover allows the organization to release unproductive or unwanted employees and to adjust the size of its workforce in situations of downsizing or restructuring. In contrast, voluntary turnover occurs when the employee initiates action to leave the organization. As most turnover models focus on individual motives for leaving the organization, the term "turnover" is generally thought of as voluntary turnover (Mobley, 1982a), thus the interchangeable use of the "turnover" and "voluntary turnover" terms in the literature. For consistency, the use of the terms "turnover" and "voluntary turnover" will be maintained as appearing in the described studies with the understanding that both terms refer to voluntary turnover.

\section{The Why and the How of Voluntary Turnover}

March and Simon (1958) provided the foundation for research into employee turnover by developing a general theory of organizational equilibrium that highlighted the need to balance both employee and organization contributions and inducements. The two major factors March and Simon (1958) used to predict whether employees would remain or leave their organization were perceived employee mobility (i.e., availability of employment alternatives) and perceived desirability (i.e., employee job satisfaction).

Since March and Simon's early theory development, researchers have developed many theories to explain and predict voluntary turnover (Griffeth et al., 2000; Maertz \& 
Campion, 1998; Porter \& Steers, 1973). Nevertheless, until recently most of these theories were based on March and Simon's "ease of movement" theory, exploring "why" individuals leave organizations. Only recently have researchers turned to address the question of "how" individuals leave organizations.

Content Models of Voluntary Turnover - Why

Many early models of employee turnover focused on single antecedents of turnover, with specific attention to the relation between overall job satisfaction and turnover (Hulin, 1966b, 1968). Researchers found a consistent but weak negative association between overall job satisfaction and turnover.

In an extensive review of the turnover literature published after March and Simon's (1958) initial job satisfaction-turnover research, Porter and Steers (1973) found a consensus that job satisfaction was a central factor in the withdrawal process. They concluded that overall job satisfaction played an important role in an individual's decision to leave or remain in the organization, but stated that "knowing that an employee is dissatisfied and about to leave does not help us understand why he is dissatisfied" (p.154). Building on this assertion, they introduced the concept of met expectations and proposed that job satisfaction was the sum total of an individual's met expectations. Porter and Steers (1973) concluded their review by suggesting that much more emphasis be placed on the psychology of the withdrawal process, a suggestion that would later spawn research exploring the quit decision process. 
Although job satisfaction has been a core component in many research models that have attempted to account for why employees voluntarily leave organizations, Mobley (1977) suggested that other variables also contributed to the act of quitting. Recognizing that job satisfaction alone accounted for only a small percentage of the overall variance in turnover (Porter \& Steers, 1973), Mobley, Griffeth, Hand, and Meglino (1979) suggested that future models of employee turnover needed to include additional variables besides job satisfaction. Moreover, Mobley et al. (1979) highlighted the fact that the construct of organizational commitment (Porter, Crampon, \& Smith, 1976; Porter, Steers, Mowday, \& Boulian, 1974; Steers, 1977) in conjunction with behavioural intentions to leave (Fishbein, 1967; Fishbein \& Ajzen, 1975) accounted for greater variance in voluntary turnover than job satisfaction alone.

In summary, early content-related research focused primarily on the extent to which single constructs, such as job satisfaction, met expectations, and organizational commitment, predicted turnover. Employee's job satisfaction, in particular, received the majority of early researchers' attention. Researchers believed that if they could understand why employees were unhappy, they would be able to provide company leaders with ways to address these concerns prior to the employee making the decision to quit, thus reducing overall turnover. A brief overview of the most frequently explored content constructs is provided. 
Job Satisfaction. According to Maertz and Campion (1998), the main content elements of most early models (pre 1980) of job satisfaction can be linked to March and Simon's (1958) concepts of an employee's perceived ease of movement (i.e., job alternatives) and the desirability of such movement (i.e., job satisfaction). Hom (2011) characterized March and Simon's (1958) seminal work as “a model of organizational equilibrium that combined ease of movement (or desirability of movement) with [job] dissatisfaction as codetermining organizational participation" (p. 326). Moreover, Hom (2011) submitted that one of March and Simon's (1958) greatest present day influences on turnover research was their acknowledgment that job dissatisfaction alone may not lead to voluntary turnover if other employment opportunities do not exist. Hom and Griffeth (1995) acknowledged that even though few studies directly tested March and Simon's (1958) model, the latter influenced and shaped much of the subsequent thinking about turnover, including that of Mobley (1977), Steers and Mowday (1981), and Lee and Mitchell (1991, 1994).

Locke (1976) estimated that at least 3,350 articles or dissertations had been published on the subject of job satisfaction. Job satisfaction was defined as “a pleasurable or positive emotional state resulting from the appraisal of one's job or job experiences" (p. 1300). Recognizing that a job is not an entity but "a complex interrelationship of tasks, roles, responsibilities, interactions, incentives, and rewards" (p. 1301 ), Locke (1976) noted that typical job dimensions such as work, pay, promotions, 
recognition, benefits, working conditions, supervision, co-workers, and company and management were generally negatively correlated with employee turnover. In an extensive review of the job satisfaction and organizational commitment literature, Griffin and Bateman (1986) identified job satisfaction as a global construct that encompassed specific facets of satisfaction, such as satisfaction with work, pay, supervision, benefits, promotion opportunities, working conditions, coworkers, and organizational practices. Moreover, they assumed that the various facets combined into an "overall orientation termed job satisfaction" (Griffin \& Bateman, 1986, p.158). According to these authors, it was generally assumed that job satisfaction was an attitude (an affect or feeling towards the job). Indeed, several meta-analyses (Cotton \& Tuttle, 1986; Griffeth et al., 2000; Hom \& Griffeth, 1985) have explored the relation between various aspects of satisfaction and voluntary turnover. Satisfaction with pay, leadership, promotional opportunities, and work were all associated modestly with less voluntary turnover, with work satisfaction having the strongest relation to turnover $\left(\rho_{1}=-.16\right)$ (Griffeth et al., 2000). Despite the large amount of research stemming from March and Simon's (1958) concept of job satisfaction, researchers have criticized this approach for its lack of predictive ability. Maertz and Campion (1998), for example, stated that models emerging in the late $20^{\text {th }}$ century rarely explained more that $25 \%$ of the variance in turnover rates.

Displeasure with the relatively weak relation between overall job dissatisfaction and voluntary turnover led researchers to identify other constructs that were more 
predictive of voluntary turnover. Constructs such as met expectations (Porter \& Steers, 1973) and organizational commitment (Meyer \& Allen, 1997; Porter et al., 1974) were introduced in an attempt to explain a greater percentage of overall variance in turnover beyond job satisfaction. Promising early results showed that organizational commitment, relative to job satisfaction, was better able to discriminate between stayers and leavers. These promising results led to a vast amount of research into organizational commitment.

Organizational Commitment. Mowday, Porter, and Steers (1982) defined organizational commitment as "the relative strength of an individual's identification with and involvement in an organization" (p. 27). Griffin and Bateman (1986) expanded the definition of organizational commitment by stating:

It is a multidimensional construct, subsuming (1) a desire to maintain membership in the organization (2) belief in and acceptance of the values and goals of the organization, and (3) a willingness to exert effort on behalf of the organization (p. 167).

As research on organizational commitment developed, Meyer and Allen (1991) conceptualized it as having three unique components: (a) affective, (b) continuance, and (c) normative commitment. Common to all three components was the recognition that commitment was a psychological state that "(a) characterizes the employee's relationship with the organization, and (b) has implications for the decision to continue or discontinue membership in the organization" (p. 67). 
In what Meyer (1997) described as the most comprehensive and cited metaanalysis of organizational commitment, Mathieu and Zajac (1990) reported that organizational commitment was highly correlated with employee turnover variables including (in order of strength): (a) intention to search for work, (b) intention to leave, and (c) actual turnover. Research continues to show modest correlations between commitment and turnover (Griffeth et al., 2000). Meyer (1997) noted that in response to the methodological advancements in commitment research, constructs such as met expectations should be re-examined.

Met Expectations. Met expectations refer to the congruence between what newly hired employees expected to experience in the workplace and what they actually experienced. Greater congruence between met expectations and actual conditions results in a lower likelihood of quitting, conversely, greater discrepancy between the two, results in a greater likelihood of quitting (Porter \& Steers, 1973). The importance of managing new employees' job expectations can be demonstrated by high early turnover rates that many organizations experience. Low met expectations have been shown to result in lower overall job satisfaction and early turnover (Wanous, Poland, Premack, \& Davis, 1992). In a comprehensive review of employee turnover, Porter and Steers (1973) focused on the role that met expectations played in different facets of job satisfaction. If the organization failed to meet this set of expectations, dissatisfaction would develop which, in turn, would increase the probability of quitting. 
In a meta-analysis exploring antecedents and correlates of voluntary turnover, Griffeth et al. (2000) reported that met expectations were negatively related to voluntary turnover $\left(\rho_{1}=-.15\right)$. The use of realistic job previews has been shown to provide new hires with a clearer understanding of what their new jobs would entail and thus help to reduce early voluntary turnover (Wanous et al., 1992).

In summary, much of the early research attention on turnover was given to content models, which focused on the reasons " why" employees voluntarily left the organization. Constructs such as job dissatisfaction, job alternatives (March \& Simon, 1958), and organizational commitment (Meyer \& Allen, 1991; Mowday et al., 1982) received the bulk of attention. Comparisons of the correlations between these constructs and employee turnover provided some understanding of turnover. However, the correlations and predictive ability of the constructs were modest at best. Emerging from these constructs was research that looked at specific antecedents of job satisfaction and/or organizational commitment; however, again the correlations between antecedents and actual voluntary turnover were modest.

It is interesting to note that while exploring the relation between work related attitudes, such as job satisfaction and organizational commitment, and the intent of employees to quit their organizations, a major development in the area of social psychology, the theory of planned behaviour (Ajzen, 1985, 1991), remained relatively unnoticed in the organizational domain. The theory of planned behavior suggests that 
individual behaviour results from behavioural intentions. Intention to perform a behaviour can be predicted by the individual's attitude towards the behaviour, subjective norms, and perceived behaviour control. Ajzen (1991) contends that an individual's intentions to perform an action, together with their perception of behavioural control account for a sizeable amount of variance in actual behaviour.

Nevertheless, researchers recognized that the traditional content models accounted for only modest amounts of the variance in voluntary turnover (Griffeth et al., 2000). These findings led Porter and Steers (1973) to call for a greater emphasis on the withdrawal process that leads to voluntary employee turnover. More work was required in combining different turnover antecedents into more complex multivariate models that attempted to understand the process that employees took prior to leaving their organizations.

\section{Process Models of Turnover - How}

Early voluntary turnover research was dominated by studies that focused on voluntary turnover as an outcome of job satisfaction and organizational commitment (Mobley et al., 1979; Porter \& Steers, 1973; Porter et al., 1974). Based on Porter and Steers' (1973) recommendation that more emphasis be placed on the withdrawal process, Mobley (1977) introduced the intermediate linkages model of turnover. In this model Mobley (1977) theorized that: 
Dissatisfaction arouses thoughts about quitting. These thoughts, in turn, prompt consideration of the expected utility of job search and costs of leaving. Barring a costly exit, optimistic employment expectations then initiate job search. The ensuing search may uncover alternatives, which are evaluated and compared. Comparisons favoring alternatives over the present job then activate quit decisions and resignations (Hom \& Griffeth, 1991, p. 50).

Mobley (1977) believed that quitting was a complex process that involved more than just job satisfaction. He proposed that a withdrawal decision process takes place between experiencing job dissatisfaction and quitting. Mobley's (1977) intermediate linkages model has been described by Maertz and Campion (1998) as the prototype of process models.

Building on his intermediate linkages model, Mobley and his colleagues (1978) developed a simplified model, in which job dissatisfaction led to a process of thinking of quitting, intention to search for a new job, intention to quit or stay, and to a final decision to either quit or stay. They believed that cognitive and behavioural events occurred between the emotional experience of job dissatisfaction and actual turnover.

Mobley (1977) introduced the idea of turnover intention into his intermediate linkages model of voluntary employee turnover. His employee turnover decision process provided a heuristic for the process that employees undertake when they start to experience job dissatisfaction. Turnover intention has been empirically shown to correlate with actual turnover (Griffeth et al., 2000) and, therefore, intentions have 
predominantly been used as a proxy for voluntary turnover, particularly when actual turnover data are not available. However, there has been considerable debate as to the appropriateness of using proxy variables as opposed to using actual turnover data.

Tett and Meyer (1993) question using intention as proxy for actual turnover, stating that the use of intent to quit as the only withdrawal criterion may not generalize well to situations using actual turnover data. In 2006, the U.S. Federal Aviation Administration commissioned a study (Dollar \& Broach, 2006) to explore whether employee's intent to leave (as reported by survey) could provide accurate estimations of future employee turnover. They concluded that intent to leave was not a good indicator of actual turnover at the aggregate level because it overestimated actual turnover. The authors did, however, note that even though intent to leave was not an accurate predictor of actual turnover, it may be a reliable indicator of early employee disengagement. Griffeth et al.'s (2000) meta-analysis of research examining the relation between employee's withdrawal cognitions and quitting demonstrated that intentions to quit explained only about $20 \%$ of the variance in actual turnover. These results were more positive than those of an earlier meta-analysis (Hom \& Griffeth, 1995) where quit intentions explained approximately $12 \%$ of the variance in actual turnover. A linear stepby-step decision process of quitting dominated research in the 1970s and 1980s (Hom, Caranikas-Walker, Prussia, \& Griffeth, 1992). However, despite their increased complexity and wider scope, models based on Mobley's intermediate linkages process 
seldom explained more than $25 \%$ of the variance in turnover (Maertz \& Campion, 1988). The lack of predictive validity offered by these models disappointed researchers and prompted turnover researchers to look beyond measures that only asked individual's about their intentions to quit. Believing that existing turnover models were too simple and that turnover research was in need of new theory, Lee and Mitchell $(1991,1994)$ proposed the "unfolding model" of voluntary turnover.

\section{The Unfolding Model}

In what Maertz and Campion (2004) called a "major advance" (p. 567) in process models, Lee and Mitchell (1991) developed the unfolding model of voluntary employee turnover. Lee and Mitchell $(1991,1994)$ believed that adding greater complexity to the major theories attempting to link job satisfaction or organizational commitment to voluntary turnover or the development of new analytical methods would only produce small gains and, therefore, contended that only the development of new theory would provide large gains in understanding the turnover process. The unfolding model moved beyond contemporary process theories by introducing the idea that the process of leaving an organization does not always result from rational decisions. The unfolding model of turnover introduced external factors into the model, thus departing from the traditional approach of focusing primarily on attitudinal factors (i.e., job satisfaction or organizational commitment) alone. 
The unfolding model is in the strictest sense a process model; however, the unfolding model contains elements of content models, in its conceptualization of "shocks". Shocks determine why people quit and consist of factors such as relocation, pregnancy, or other life events that can prompt an individual to voluntarily leave an organization. The introduction of shocks into the model provided an alternative to the traditional approach that dissatisfaction or potential job alternatives were primary in the turnover process. Three key elements of the process require explanation. These key elements are shocks, scripts and image theory, all of which play a key role in Lee and Mitchell's (1991, 1994) unfolding model.

Shocks. Lee and Mitchell (1991) described a shock or "shock to the system" as a specific event that causes an employee to reflect on their current situation and to engage in deliberations about voluntarily leaving the organization. The shock could be expected or unexpected; surprise is not an essential element. A shock may be considered positive, negative, or neutral. Examples of positive shocks may be winning the lottery or the birth of twins. A negative shock may include a company merger that results in drastic changes to the work environment or ethical or moral violations (unethical behaviour of current company). Neutral shocks' may include an unsolicited job offer for which the employee may initially feel very indifferent, however, upon reflection decides to accept. In all cases, however, the status quo is disrupted by the shock in a way that motivates an employee to ponder leaving the organization. 
Scripts. Another key element in the unfolding model is the notion of scripts. Lee and Mitchell (1991) proposed that after receiving a shock, some employees followed a pre-determined plan of action that the employee had created to deal with potential future shocks. For example, after a long military career that has included numerous postings (job transfers), a military member may decide to quit if posted again. Very little mental deliberation or time would be required should the member be posted, upon being told of the posting, the script would be enacted and the member would quit.

Lee et al. (1999) suggest that anticipating an event may be very different than actually experiencing it. As an example, some employees may have a pre-existing script to quit if they are not promoted during the next promotion cycle. However, several unexpected monetary setbacks may make it impossible to enact the script if they are not promoted, thus forcing them to remain with the organization.

Image theory. The third integral component of Lee and Mitchell's $(1991,1994)$ unfolding model of employee turnover is the decision-making process. Mitchell and Beach (1990) developed a model of decision making that they called "image theory". The authors believed that most decisions involved a non-analytic rapid decision making process that relied on an individual's intuition. Image theory suggests the decision makers have a set of three distinct images consisting of: (a) value images (principles), which are a set of general values, standards, and principles that defines a person; (b) trajectory images (goals), which are a set of goals that motivates and drives an 
individual's behaviour; and (c) strategic images (plans), which are a set of behavioural tactics and strategies that an individual implements into their daily lives in order to attain their goals. Beach and Mitchell (1987) argued that the decision making process involves comparing available employment alternatives against these three images.

Image violations occur when an individual's values, goals, and plans for goal attainment are incompatible with an occurring shock. For instance, learning she has become pregnant may prompt an employee to quit, as working while raising small children violates her family values. The shock of becoming pregnant immediately triggered a violation of deeply held values and very little deliberation was required prior to deciding to quit. Neither job satisfaction nor job alternatives were considered prior to the quit decision. Lee and Mitchell $(1991,1994)$, incorporate image violations into their decision paths, specifically paths $2,3,4 \mathrm{~A}$ and $4 \mathrm{~b}$ require the employee to compare shocks against currently held images. A description of each of the unfolding model's decision paths is provided in Figure 1.

The Unfolding Model - Decision Paths. In their original conception, Lee and Mitchell's (1991) unfolding model consisted of four distinct pathways to voluntary turnover; however, it was later modified to include a fifth decision path. A summary of the five paths follows: 

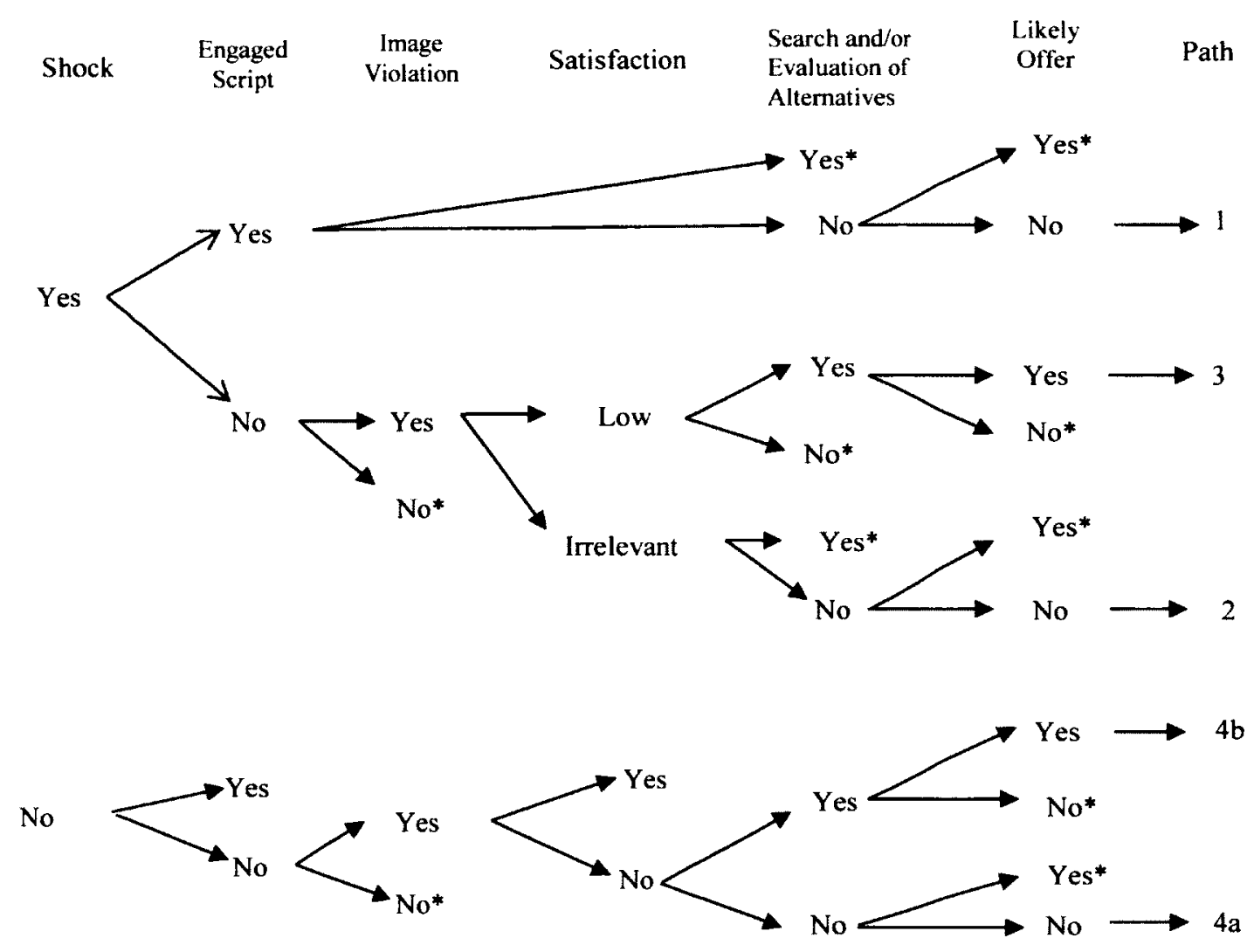

Figure 1. The Unfolding Model of Voluntary Turnover. An asterisk (*) indicates that the route is not classifiable and that it represents a theory falsification - a way in which an individual could leave an organization that would not be part of one of the model's paths. Adapted from "The Unfolding Model of Voluntary Turnover: A Replication and Extension," by T.W. Lee, T.R. Mitchell, B.C. Holtom, L.S. McDaniel, and J.W. Hill, 999, Academy of Management Journal, 42, p. 451. Copyright 1999, by the Academy of Management Journal. 
Decision Path 1. The employee experiences an initial shock. The shock compels the employee to construct a decision frame around the shock to interpret the way forward. The employee's immediate reaction to the shock will be guided by existing personal characteristics and experiences. A second process resulting from the shock will be a memory search for any prior decisions, rules or learned responses from experiencing similar previous shocks. If employees have experienced similar shocks in the past, they will evaluate past decisions and judge whether the decisions were appropriate or not. If past decision frames exist that are identical or very close to the current one where quitting was the outcome, it is very likely that the employee will respond in the same fashion to the current shock. Very little mental deliberation will be required. If no match is found, a different decision path is taken. Therefore, Decision Path 1 consists of (a) a shock, (b) a match with a previous decision or rule violation, and (c) a script-driven decision. Decision Path 1 does not involve any images, evaluations of job alternatives, or consideration of current level of job satisfaction. Lee and Mitchell (1994) point out that decision path 1 is very different from traditional turnover models. Job satisfaction and organizational commitment, two facets that are typically considered antecedents to voluntary employee turnover, are not included in the decision path. The quit response is made with minimal deliberation and not based on the availability of alternative jobs or an evaluation of the current job. The shock alone provides the impetus for the employee to 
quit based on pre-existing scripts. The shock need not be surprising or negative (Lee, Mitchell, Wise, \& Fireman, 1996); indeed, it could be as simple as a planned pregnancy (Lee et al., 1996), on the part of a woman who has a personal script of staying home with her child for a period.

Decision Path 2. Similar to decision path 1, decision path 2 commences with a shock; however, in this path, there is no pre-existing memory of a similar shock or an appropriate script that can be recalled from memory. As a result the employee is forced to engage in additional mental deliberation on how to react to the shock. If the shock is unexpected, the decision to leave or stay with the organization is made without having an alternative job offer and therefore, decision path 2 is considered a push decision. In decision path 2, Lee and Mitchell (1994) theorize that employees initiate a series of decisions in which they evaluate the effects of the resulting shock against their currently held values, trajectory, and strategic images. If the shock is such that it violates any of the images held by the employee, the violation will result in quitting. If the shock does not violate any of the pre-existing values, the employee may choose to stay. The employee must decide whether the shock can be integrated or fit with existing values.

As noted previously, image theory describes this process as a compatibility test. If the shock violates one of the images but the employee chooses to stay, Lee and Mitchell (1994) theorize that a change to the image being violated takes place. As an example, a military member may have decided that they are not willing to leave their 
current geographical area. If they are told that they will be required to move (shock), the result would be voluntary release from the military. However, a situation may arise where they have an opportunity for an overseas assignment (in a particularity appealing location, one that was previously unavailable and therefore not included in their strategy image). The opportunity to move to the appealing location triggers a change in their image to one that would include the overseas move. In summary, decision path 2 consists of a shock, no match to a similar past event, and no alternative job offer.

Decision Path 3. As with decision path 2, a shock is received that initiates a memory probe, which results in no recollection of an earlier similar type shock. As in decision path 2 , the shock is evaluated with existing images. The main difference between decision paths 2 and 3 is that in decision path 3 , an alternative job offer exists. The decision to stay or leave the organization is considered knowing there is a ready alternative to staying. As in other decision paths, the shock can be positive, negative or neutral, but the alternative job offer changes the type of decision from a push (experienced in path 2) to a pull decision. The alternative job offer is seen as having a pulling effect towards voluntarily leaving the organization.

Decision Path 4. In this decision path, the decision to leave the organization is a result of an on-going deliberation about the merits of staying versus leaving the organization. Unlike the previous decision paths, no shock is experienced. Initiation of decision path 4 may start with subtle changes over time to the organization or the 
individual that result in a lack of fit with the employee's values or trajectory images. These violations may cause the employee to start a reassessment of staying with the organization. If the subtle changes have an effect on the employee's satisfaction with the current job, the employee may look for other employment. Alternatively, decision path 4 may be initiated through an affective process that bypasses any cognitive deliberations involving potential image violations. The dissatisfaction with the organization is a direct result of a negative affective response to the organization (i.e., an accumulation of dissatisfaction with company leadership). Lee and Mitchell (1994) consider the two separate paths within decision path 4 as sub-paths ( $4 a$ and $4 b$ ). Initiation of path $4 a$ commences without a shock and results from changes over time that violates value or trajectory images. The cognitive process involves assessment of changes occurring over time that result in a determination of a "no fit" conclusion. The unfolding model maintains that in decision path $4 \mathrm{~b}$, the lack of fit results in job dissatisfaction, lower organizational commitment, increased job search activity and a stronger intention to leave the organization. However, there are instances (decision path 4a) where accumulation of negative affect results in the employee leaving the organization without considering any job alternatives. Simply, they realize they are unhappy and they quit.

In their original version of the unfolding model, Lee and Mitchell (1991) did not associate specific decision paths to any given type of shock. In a later version, Lee et al. (1999) provided some directional hypotheses based on each shock-induced decision path. 
They suggested that shocks, which induce path 1 decisions, are more personal in nature, while in path 2 , quitting is theorized to be in response to an event (usually an undesirable one), thus it is expected that a negative shock will be the cause. In path 3 , it is anticipated that shocks will involve more organizational issues rather than personal ones.

In the original version of the unfolding model (Lee \& Mitchell, 1991) quitting through the use of scripts in response to a shock was limited to decision path 1 and not thought to be present in the other paths (2-4a). However, in later versions, Lee et al. (1999) felt that although the nature of scripts in the quitting process was well defined in path 1 , it was ambiguous in the other paths. They refined the unfolding model by suggesting that scripts may be more prevalent than first thought. Although the authors maintain that the direct effect (quitting) as a result of the script is limited to path 1 , a script may still be present in the other paths and may coexist with other factors. An employee may have developed a script for leaving in response to a specific shock but because of circumstances may choose not to employ the script.

In an attempt to empirically test the unfolding model, Lee et al. (1996) interviewed 44 nurses who had recently voluntarily quit their jobs. They were able to classify $33(62.5 \%)$ of the nurses into one of the four decision paths. However, 11 of the nurses did not fit into any of the decision paths. Lee et al. (1999) postulated the lack of fit into any of the prescribed paths represented "potential conceptual ambiguities in the model... [and] several undefined gaps" (p.452). After their first attempt to empirically 
test the unfolding model, Lee et al. (1999) noted that some meaningful points emerged. Forty-five percent of nurses quit without having actual job offers, a process that fell outside of traditional turnover theories. Shocks played a key role in the quitting process, in that, many of the shocks experienced by the nurses were unrelated to their jobs or organization. Moreover, in many instances the shocks were of a positive nature, suggesting the reasons for quitting did not always result from dissatisfaction with the job or organization. Finally, Lee et al. (1996) suggested that future research should examine differences in the elapsed time between first thinking about quitting and actually quitting. In a follow-up study that addressed earlier noted conceptual ambiguities and undefined gaps, Lee et al. (1999), replicated work by Lee et al. (1996) and were able to increase the number of employees classified into specific paths. Overall they were able to classify $92.6 \%$ of the 229 accountants who had voluntarily left their jobs into one of the five decision paths. Lee et al. (1999) extended the unfolding model by essentially splitting decision path 4 into two separate paths (4a and 4b). Moreover, Lee et al. (1999) found quitting occurred quickest in paths 1 and 2. Moreover, when shocks were experienced, shock characteristics were different for each path. Lee et al. (1999) concluded that when employees quit an organization they use "distinct and systematic psychological processes or paths" (p. 458). When Lee et al. (1999) compared nurses who quit from Lee et al.'s (1996) study and accountants who quit from their current study; they found that the decision paths taken in the quitting process differed between the two 
groups. They suggested that different occupational groups have different patterns of quitting.

Since its inception (Lee \& Mitchell, 1991), the unfolding model has been empirically tested and, as noted above, some conceptual ambiguities and theoretical gaps were identified. In response, Lee et al. (1999) addressed the noted shortcomings by introducing modifications and empirically testing their extensions to the original model. Modifications were made to job alternatives, job offer as a shock, search and evaluation, and decision path speed.

Job alternatives. In its original configuration, the unfolding model suggested that job alternatives were considered in path 3 (shock results in search and evaluation of job alternatives) and path $4 \mathrm{~b}$ (reduced job satisfaction results in search and evaluation of job alternatives). However, Lee and Mitchell (1994) did not clearly define the nature of the job alternative, but it was implied that a specific job offer was available. In the revised model, the paths remain the same but Lee et al. (1999) suggest that when an employee considers quitting for another job, it is not necessary for the employee to be in possession of an actual job offer. Lee et al. (1999) contended that an alternative job only needs to be perceived by the employee as highly probable. They also suggest expanding the meaning of job alternative to include alternative non-work options and other forms of work (although they do not specify what these would include). 
Job offer as a shock. Lee and Mitchell $(1991,1994)$ considered the shock of an unsolicited job offer to only be relevant to path 3 because they felt mental consideration of the unsolicited job offer would follow the initial shock. Path 1 was not appropriate because the employee was following a scripted response, path 2 was not relevant because the employee did not conduct a search, and path 4 was not relevant because quitting resulted from decreasing levels of job satisfaction, and did not result from a shock. In their modification to the model, Lee et al. (1999) suggested that an unsolicited job offer could initiate a pre-existing script that results in quitting without any further mental deliberation. They provide an example in which an employee may have turned down an unsolicited job offer in the past but decided to accept it if it was ever offered again in the future. Given this new understanding they accept that an unsolicited job offer can be included as a shock in paths 1 and 3 as long as an enacted script is not accompanied by an active search or evaluation of an alternative job. If an active search or evaluation occurs, the quitting process would follow path 3 .

Search and evaluation. Initially, Lee and Mitchell (1991) proposed that search and evaluation of alternative jobs occurred together. Lee et al. (1999) suggested the two may happen independently of each other and propose they be decoupled from each other in the process. They suggest that it is quite possible for an employee to search for a job and not find one to evaluate or they may receive an unsolicited job offer (no search) and be required to only conduct an evaluation. 
Decision Path Speed. In Lee and Mitchell's (1991) original configuration, they suggested that two factors affected the speed with which the decision paths unfolded. The first factor consisted of the amount of mental deliberations involved in each path. Fewer mental processes meant the path unfolded more quickly. The second factor was concerned with the information available in each path. If scripts or images were available the decision process would unfold more quickly, however, if external information such as the availability of jobs or the requirement to evaluate alternative jobs was required the process would unfold more slowly. Lee et al. (1999) separated them and measured them in two sequential time frames that varied by amount of internal or external control. The first time frame considered the period between employees' initial thoughts of quitting and their subsequent decision to quit. This period is considered more internal in nature, as the employee decides whether they want to leave or not. The second time fame considered the time between the decision to quit and actual quitting. This period is considered more external in nature, as employees' actual ability to quit might depend on their ability to obtain alternative employment.

In summary, Lee and Mitchell's unfolding model $(1991,1994)$ has been praised as innovative and a ground-breaking conceptualization (Hom, 2011). Since inception, Lee and Mitchell's $(1991,1994)$ unfolding model has undergone some modifications to address previously identified conceptual ambiguities and theoretical gaps. Although the unfolding model has only received limited empirical attention, the model has shown 
potential to accurately describe employee turnover. Moreover, the unfolding model has provided a template for exploring the integration of both content and process theories.

\section{An Integration of Content and Process Models}

Although some overlap between the content and the process models has occurred (Lee \& Mitchell, 1994), relatively little research has been devoted to combining the two models. Most existing research models focused primarily on explaining either why or how employees quit an organization. Lee and Mitchell's unfolding model went beyond existing models by introducing elements of both content and process into their model. However, the unfolding model did not attempt to integrate the why and how in exploring voluntary turnover. Maertz and Campion (2004) recognized this short falling, calling it a "blind spot" (p. 566) in turnover research. Moreover, they proposed that by examining the specific motives behind why employees left organizations, insight may be gained as to the specific decision processes they might engage in before leaving the organization. In short, the authors hypothesized that "certain motives may cause certain types of processes to occur more frequently than others" (p. 566). Using elements of the revised unfolding model (Lee et al., 1999), Maertz and Campion (2004) identified motivational forces for reasons to quit (content - why) and four generic types of decision making (process- how). They hypothesized that the motives for quitting would be unique to the individual generic decision types. In their study of 159 quitters, two distinct measurements were used. Participants underwent an interview to determine what generic 
decision type was used when they quit their last job (impulsive quitters, comparison quitters, pre-planned quitters and conditional quitters). Participants were then asked to complete a follow-up survey designed to measure motivational forces (divided into eight possibilities) behind the quit decision. Maertz and Campion (2004) hypothesized that each generic decision type would be comprised of unique levels (high or low) of the different motive forces at the time of quitting. Maertz and Campion (2004) concluded that different turnover motives were systematically related to different decision process types. Given that content and processes are systematically related, Maertz and Campion (2004) proposed that new content by process models could be designed to create a more precise and accurate picture of voluntary turnover and stimulate empirical research. Maertz and Campion concluded that their approach of combining content and process models provides a new direction for theoretical research. Moreover, understanding the reasons why an individual leaves an organization can provide insight into the different decision processes undertaken by the employee prior to leaving. Understanding how an employee might leave the organization based on specific content might provide managers with the opportunity to mitigate voluntary turnover before it happens. Maertz and Campion (2004) concluded their study by expressing the hope that their research would stimulate more research integrating content and process models.

In an effort to expand research on the unfolding model, Holtom and Inderrieden (2006) explored integrating Lee and Mitchell's (1994) unfolding model with job 
embeddedness (Mitchell, Holtom, Lee, Sablynski, \& Erez, 2001). Moreover, the authors added to the literature by expanding on what was previously known about "shocks." They found that many of the shocks employees experienced resulted primarily from issues within the organizations control (i.e., relocation or promotion issues). They believed that if organizations could identify the shocks that employees might experience prior to the actual shock event, the organization might be able to address employee concerns and lessen their impact. In a review of the turnover and retention literature, Holtom et al. (2008) called for an integration of Maertz and Campion's (2004) model of turnover with the unfolding model. They suggested exploring how events influence employee's reasons for quitting (motives) and the decision paths that lead to quitting. Moreover, they called for additional research exploring the ways that employees initiate and enact the process of quitting.

\section{Voluntary Turnover in the Military}

For the few studies that have examined voluntary turnover using military samples, questions have been raised as to the generalizability of the results to a civilian population. Research has shown that military withdrawal may differ from civilian (Carsten \& Spector, 1987). Hom et al. (1992) found the relation between job satisfaction and search for alternative employment was different between military and civilian populations. Lytell and Drasgow (2009) cite concerns over the potential moderating effects of the differences between military and civilian samples on turnover relationships. Most studies 
using military samples to study voluntary employee turnover have been concentrated within the content model, focusing on job satisfaction and organizational commitment (Holt et al., 2007).

Holt et al. (2007) was the only study to date that I was able to find that combined content and process models using a military sample. Using a sample of 182 United States Air Force Officers who voluntarily left the U.S Air Force, Holt et al. (2007) used a modified version of Lee et al.'s (1999) unfolding model to explore how specific shocks resulted in distinct paths to turnover. They found that $83 \%$ of turnover decisions were captured by their modified model. Moreover, Holt et al. (2007) found that $62 \%$ of U.S. Air Force officers experienced a shock prior to quitting the U.S. Air Force. Their results helped solidify Maertz and Campion's (2004) assertion that both content and process theories, when integrated, provide supplemental information in understanding voluntary turnover.

In summary, past research provides limited empirical support for both the unfolding model (Lee \& Mitchell, 1994) and the improved understanding of voluntary turnover that comes from integrating content and process models of employee turnover. However, empirical investigation of the unfolding model and the integration of content and process models are still sparse. The present study will attempt to build upon the research that has already attempted to integrate content and process models. 


\section{The Present Study}

The Canadian Forces is an all-volunteer force composed of Regular (full time) and Reserve forces (part time); however, for the purposes of this study only regular force personnel were included. The Canadian Forces (regular force) has a population of approximately 68,000 military members across the Royal Canadian Navy, the Canadian Army, and the Royal Canadian Air Force. As with civilian organizations, voluntary and early turnover are of concern to the leaders in the Canadian Forces. High early career turnover rates have proven to be very costly for the military and their reduction was recently identified as a top priority by the Chief of Military Personnel (Canadian Forces top Human Resources executive) for the Canadian Forces (Otis \& Straver, 2008).

Voluntary turnover poses additional challenges within a military context. Specifically, unlike civilian organizations, the Canadian Forces imposes terms of service for all members joining the military. These terms of service provide that, in return for military training, newly hired recruits agree to serve for a pre-determined amount of time. Initial mandatory service times vary between 3 and 9 years depending on the occupation and whether the military members are officers or non-commissioned members. After the initial terms of service have been reached, members have the option to re-sign or voluntarily leave the military; these points in time have been described as gateways. 
With the exception of the initial basic engagement ${ }^{1}$ (replaced in 2005 by variable initial engagement) terms of service are not binding periods of service that must be completed; military members can officially request a voluntary release prior to completing their terms of service. The final decision whether to release the member is at the discretion of the Canadian Forces; the needs of the service are given first priority when deciding to approve or deny the request. Typically once members have completed their initial terms of service, requests for voluntary release are granted within six months or less. Eligibility for an immediate annuity ${ }^{2}$ (pension) after 25 years of service dramatically increases voluntary turnover once military members become eligible for an immediate pension annuity (ADM HR Mil Instruction 05/05). Unlike civilian organizations where most, if not all, personnel must wait until a pre-determined retirement age (usually 65 ) to receive pension benefits, Canadian Forces personnel commence receipt of their pension benefits immediately upon release. Past attrition research has shown that attrition rates spike at these gateways (Otis \& Straver, 2008). Service in the military requires very unique skill sets that can only be obtained through military service. Although the leadership qualities and experience gained through military service are very transferrable to civilian

\footnotetext{
' Generally once all military training has been completed, members are expected to serve until the completion of their initial terms of service. However, there are circumstances where voluntary release will be authorized prior to completion of terms of service.

${ }^{2}$ Prior to 2005 , military members were eligible for an immediate annuity after 20 years of service.
} 
organizations, civilian workers are unable to assume a similar role within the military without prior military training. Progression in rank is a direct reflection of experience and competence, comprised of very specific experiences and knowledge.

Whereas Holt et al. (2007) only looked at U.S. Air Force officers in their study and their sample; the current study will expand beyond that by exploring both officers and non-commissioned members. Lee et al. (1999) found that quit paths taken were different between nurses and accountants and they suggested that different occupational groups have different paths for leaving. This study will examine whether these differences exist between officers and non-commissioned members. Moreover, as no study has used Canadian Forces personnel in the integration of content and process models, the current study will fill that gap by exploring that population.

Using archival data from the Canadian Forces Exit Survey completed by Canadian Forces members who voluntarily left the Canadian Forces, the present study examined why Canadian Forces members quit the organization and explored the process they used to make their decision. The idea of shocks, introduced in Lee and Mitchell's (1994) unfolding model, was used to explore the reasons military members first thought of quitting and what made them finally decide to quit, thus attempting to understand why Canadian Forces members voluntarily leave the Canadian Forces. Attempting to understand how quit decisions are made, the shock events and decisive factors that influenced the Canadian Forces members in their decision to voluntarily leave the 
organization were also explored in terms of the decision-making process, along with the speed and difficulty of the quit decisions. In this way, this study explored the theoretical extension of the unfolding model in terms of decision path speed and amount of mental deliberations involved in the decision-making. The understanding of the specific motives (i.e., reasons for wanting to leave and for leaving) at play in the voluntary turnover process and the process itself would contribute to the understanding of the why and the how of voluntary turnover in the Canadian Forces and would enable managers and senior officers in the military to proactively develop interventions to reduce voluntary turnover. As noted by Maertz and Campion (1998), the use of qualitative measures in studying the quitting process in Lee and Mitchell's (1994) unfolding model has been viewed as a departure from the use of more traditional quantitative methods. Hom (2011) suggested that as a result of the unfolding model, Lee and Mitchell (1994) popularized the use of qualitative methods. Maertz and Campion (2004) were advocates for the continued use of qualitative methods in order to fully understand the quitting process. Since the introduction of the unfolding model there has been a call by researchers to enhance our knowledge of the quitting process through a greater use of qualitative research. Maertz and Campion (1998) opined that creative approaches, such as the use of qualitative measures, need to be used in order to "investigate the many nuances and complexities of the [quit] decision" (p. 75). Moreover, they stated that without the use of 
qualitative methods the full depth and complexity of the decision process will never be fully understood.

Using open-ended questions from the Canadian Forces Exit Survey that ask departing members about what first prompted them to think about leaving and what finally made them decide to leave, the present study attempted to determine whether the first thoughts of leaving were consistent with the factors that eventually influenced members to quit. To the extent possible, the decision-making paths of Lee et al.'s (1999) unfolding model were examined to understand whether the decision to quit resulted from a "shock" event. Of those responses that were classified as shocks, I was interested in exploring the nature of the shocks; specifically, whether the shocks initiated a script or image violation and whether the shocks were a result of a push-factor (i.e., a factor within the organization's control) or a pull-factor (i.e., a factor outside of the organization's control). Moreover, I was interested in exploring whether the factors that initially influenced the military member to consider quitting were consistent with or different from the factors that eventually influenced them to quit. Using close-ended questions that asked quitting members how difficult it was to make the decision to leave, and how long it took them to make their final decision to leave, this study explored the decision making process by tapping into the dynamics of the decision making process and associated factors. 


\section{Method}

\section{Sample}

The total number of military members who voluntarily released from the Canadian Forces between 4 June 2008 and 31 August 2011 was 7,794. Overall, 1,751 military members completed the exit survey; the response rate was $22.46 \%$. However, after data cleaning the final sample was composed of 1,179 respondents. The highest number of respondents were between the ages of $41-45$ years old $(n=221)^{3} ; 86.4 \%(n=$ $1019)$ were men, $13.3 \%(\mathrm{n}=157)$ were women, and $.3 \%(n=3)$ were missing information on gender. There were $986(83.6 \%)$ members who indicated English as their first official language, whereas $191(16.2 \%)$ indicated French and $.2 \%(n=2)$ were missing information on their official language. Rank structure of participants was $68.2 \%$ $(n=804)$ non-commissioned members and $31.8 \%(n=375)$ Officers. The mean time served in the Canadian Forces prior to exit was 15.8 years $(S D=11.0$ years). To explore for potential response bias, I compared the study sample demographics with Canadian Forces population demographic data (Messervey, Howell, Gou, \& Yelle, 2011 ). Comparisons revealed that the study sample demographics were very similar to the Canadian Forces population demographics.

\footnotetext{
${ }^{3}$ The age of respondents was a categorical variable in the survey thus not allowing for a description of the age range of respondents.
} 


\section{Procedure}

Data collection. This investigation used archival data from the Canadian Forces Exit Survey that was administered to Canadian Forces personnel who voluntarily exited from the Canadian Forces from 4 June 2008 to 31 August 2011. During the release process (once the member has formally requested to leave the organization), all Regular Force ${ }^{4}$ Canadian Forces personnel undergoing voluntary release are requested to complete the Canadian Forces Exit Survey. The exit survey is computer based, participation is voluntary, and all personnel remain completely anonymous with no personal identifying questions asked. Administration of the Canadian Forces Exit Survey was authorized by the Director General Military Personnel Research and Analysis within the Department of National Defence/Canadian Forces in accordance with CANFORGEN 145/02 ADMHRMIL 079 UNCLASS 131028Z, authorization number 717/07. Releasing personnel complete the exit survey at the Base Personnel Selection Office located on the military establishment from which they are releasing. Once the survey is completed the results are electronically stored within a database held at Director General Military Personnel Research and Analysis in Ottawa, Ontario.

\footnotetext{
${ }^{4}$ The Canadian Forces are comprised primarily of regular and reserve force personnel. In layperson terms regular force personnel are considered full time whereas reserve force personnel typically serve on a part time basis.
} 


\section{Measures}

Canadian Forces Exit Survey. The Canadian Forces exit survey was designed to help identify the reasons why Canadian Forces members voluntarily leave the Canadian Forces. Moreover, the exit survey provided an opportunity to examine the process (how) military members used to leave. To capture the initial reasons why the exiting member considered quitting, the following question was used: "What first prompted you to think about leaving the CF?" "What finally made you decide to leave the CF?" was explored to understand the factors that prompted the exiting member to finally quit. Both questions were open-ended and allowed respondents to provide any comments they thought were appropriate. The participants were not limited in how long or short they could make their responses.

The quitting process was measured with two items: "After your first thoughts about leaving, how long did it take for you to make the final decision to leave the CF?" There were six response options including: a) don't know, b) less than a month, c) months (between 1 and 12 months), d) 1 year \& 6 months, e) years (between 2 and 10 years), and f) more than 10 years, (where blanks were present, respondents were to fill in the exact number of months or years). The "How difficult was it for you to make the decision to leave the CF?" item was rated on a 4-point Likert scale ranging from very difficult (1) to very easy (4). Questions aimed at collecting demographic information about the respondents were also asked: "How many years have you served (Combined 
Regular and Reserve Force)?" which was rated with two response options: (a) Less than one, and (b) ___ years. "What is your age?" had the response options of a) under 20 years, b) 20-25 years, c) 26-30 years, d) 31-35 years, e) 36-40 years, f) 41-45 years, g) 46-50 years, h) $51-55$ years, and i) over 55 years. Finally, "What is your first official language?" had the response options of a) English or b) French.

\section{Results}

\section{Preliminary Analysis}

Data screening. The initial data set of 1,751 respondents was examined to ensure it was comprised of regular force members who voluntarily quit the Canadian Forces. As a result, a total of 207 participants were excluded from analysis since they did not meet these criteria. They were either reserve force members or they had left the forces for other than voluntary reasons (i.e., medical release). Survey responses were then screened for out of range values, patterns of responses, missing values, and univariate and multivariate outliers.

Missing values analysis. The data were examined for cases in which large amounts of responses were missing. A total of 98 cases were identified in which participants failed to complete $70 \%$ or more of the questionnaire, those cases were deleted. Inspection of the qualitative responses revealed 96 cases missing data from either question one ("What first prompted you to think about leaving the CF?") or question two ("What finally made you decide to leave the CF?"); cases with data missing 
from either question were deleted. Finally, 134 cases were deleted as the qualitative responses (either in question one or two) did not contain sufficient information to identify the push/pull group to which they should belong. The remaining sample consisted of 1,216 participants.

Using the SPSS missing value analysis function, an analysis of missing data was conducted to determine whether any problems existed with the pattern of missing data at either the variable or case level. Overall $2.7 \%(n=37)$ cases had some missing data; component item was missing 32 cases $(2.3 \%)$, release item had four missing cases $(.3 \%)$, years of service had one missing case (.1\%), while leave time and leave difficulty were not missing any cases. The analysis revealed that no individual variable contained more than $5 \%$ missing data; as such, the missing data was assumed to be missing completely at random (MCAR). The data were visually examined specifically looking for potential patterns of missing data. The examination did not uncover any apparent systematic relationships between variables with missing data.

The missing data in each variable were assessed and the data were analysed using the omnibus Little MCAR test. A non-significant relationship was found for the variables, $\chi^{2}=20.73, d f=15, p=.15$. To accommodate for missing data, casewise deletion was used, thus reducing the overall number of respondents to 1,179 . Given the relatively small amount of missing data and their dispersion throughout the data set, it was concluded that the missing data did not contain any patterns. 
The data were screened to explore whether the assumptions of the independent $t$ test were satisfied. An informal test for normality was conducted by producing frequency distributions and histograms in SPSS for the following three variables: "After your first thoughts of quitting, how long did it take you to make a final decision?" (identified hereafter as leave time), "How difficult was it for you to make the decision to leave the CF?" (identified hereafter as difficulty of quit decision), and "How many years have you served? (Combined Regular and Reserve Force)" (identified hereafter as years of service). Visual inspection of the histograms revealed departures from normal distributions in all three variables. A Kolmogorov-Smirnov test of normality was conducted using SPSS. Significant levels of non-normality $(p s<.001)$ were obtained for all variables. However, because of the very large sample size used in this study, the results were susceptible to a small standard error, thus increasing the likelihood making Type I errors. Field (2009) states, "significant values arise from even small deviations from normality (p.139)." To obtain a more accurate picture of skewness and kurtosis, and following Tabachnick and Fidell's, (2007) guidelines, scores for all variables were converted to $z$ scores. Skewness and kurtosis values (displayed in that order) for each variable were divided by their standard error resulting in the following absolute values: In the shock groups: leave time $(8.88,-3.20)$, difficulty of quit decision $(1.63,-4.74)$, years of service $(-2.41,-5.90)$; In the non-shock groups: leave time $(5.36,-5.69)$, difficulty of quit decision $(.63,-5.26)$, years of service $(3.11,-5.96)$. 
As unequal sample sizes and distribution non-normality were present in the officer/non-commissioned member groups and the push/pull factor groups, nonparametric tests were used.

Outliers. Informal visual examinations of the stem and leaf and box plots revealed several potential univariate outliers. However, in a more formal exploration for univariate outliers, $z$ scores were created for all the variables used in this study, and examination of the scores revealed no $z$ scores exceeded $3.29(p<.001$, two tailed test), thus indicating no univariate outliers were present.

\section{Main Analysis}

Qualitative analyses. The final dataset, both qualitative and quantitative, was entered into Microsoft Excel. When qualitative responses were provided in French, the translate function within Microsoft Excel was used to translate into English. To ensure accuracy of translation, a native French speaker reviewed the translations. A total of 83 French responses were included in the final dataset.

The initial analysis consisted of examining the question "What first prompted you to think about leaving the CF?" and coding the responses as either a shock or non-shock event (a detailed description of the coding process used is described later). Responses that were deemed to consist of a shock were further examined to explore the nature of the shock and coded as either push (the shock involves factors internal to the organization) or pull (the shock involves factors external to the organization). The push and pull 
categories of responses were analysed separately to identify specific themes within these categories of responses. Similarly, non-shock related responses were coded into themes specific to what first made Canadian Forces members think about quitting.

Participants' responses to the second question "What finally made you decide to leave the CF?" were then analysed within the two groups of responses "shock"/"nonshock" coded from the answers to question one, to determine the nature of the factors that finally made the Canadian Forces members decide to quit (i.e., whether these factors represented a push or a pull from the organization). In other words, the shock event for the entire sequence was determined by Question One, i.e., if a shock event precipitated the original thoughts of quitting, the response to the second question was also coded as involving a shock. Conversely, if a non-shock event was responsible for the original thoughts of quitting, the response to the second question was also coded as a non-shock event.

Responses coded as shocks were then further examined and coded within either a push or pull category. Afterwards, each category (push and pull) was individually examined to identify common themes specific to what finally made the Canadian Forces members decide to quit. The responses coded as non-shock were explored and coded into themes specific to what made the Canadian military members finally decide to quit.

Finally, the sequence of the quit decision process was explored by examining the reasons for respondents' initial thoughts of quitting with the reasons for their final 
decision to quit. For example, the reasons for first thinking about quitting may be internal to the organization (e.g., location of next posting, career management decision), whereas the reasons for the final decision to quit may be external to the organization (e.g., job offer or enrolment in university). In this example, the sequence of factors would be coded as push-pull. Whether respondents' initial reasons for thinking of quitting were consistent (i.e., push-pull or pull-push) or changed during the decisionmaking process (i.e., push-push or pull-pull) was of primary interest.

To facilitate a better understanding of the quitting sequence, a visual representation (see Figure 2) and a written description of the resulting eight push/pull groups are provided. The eight push/pull factor groups are:

Shock - Push/Push Group. Respondents in this group identified a shock push event as first prompting them to consider quitting. Respondents then identified a push factor as the actual reason for quitting. For example, a military member may have received an unwanted posting instruction (push) that prompted them to consider quitting, but then decided that he/she would rather remain in the CF and believed that he/she might have been able to have the posting instruction changed. However, when the military refused to change or cancel the posting, the member to quit (push). 

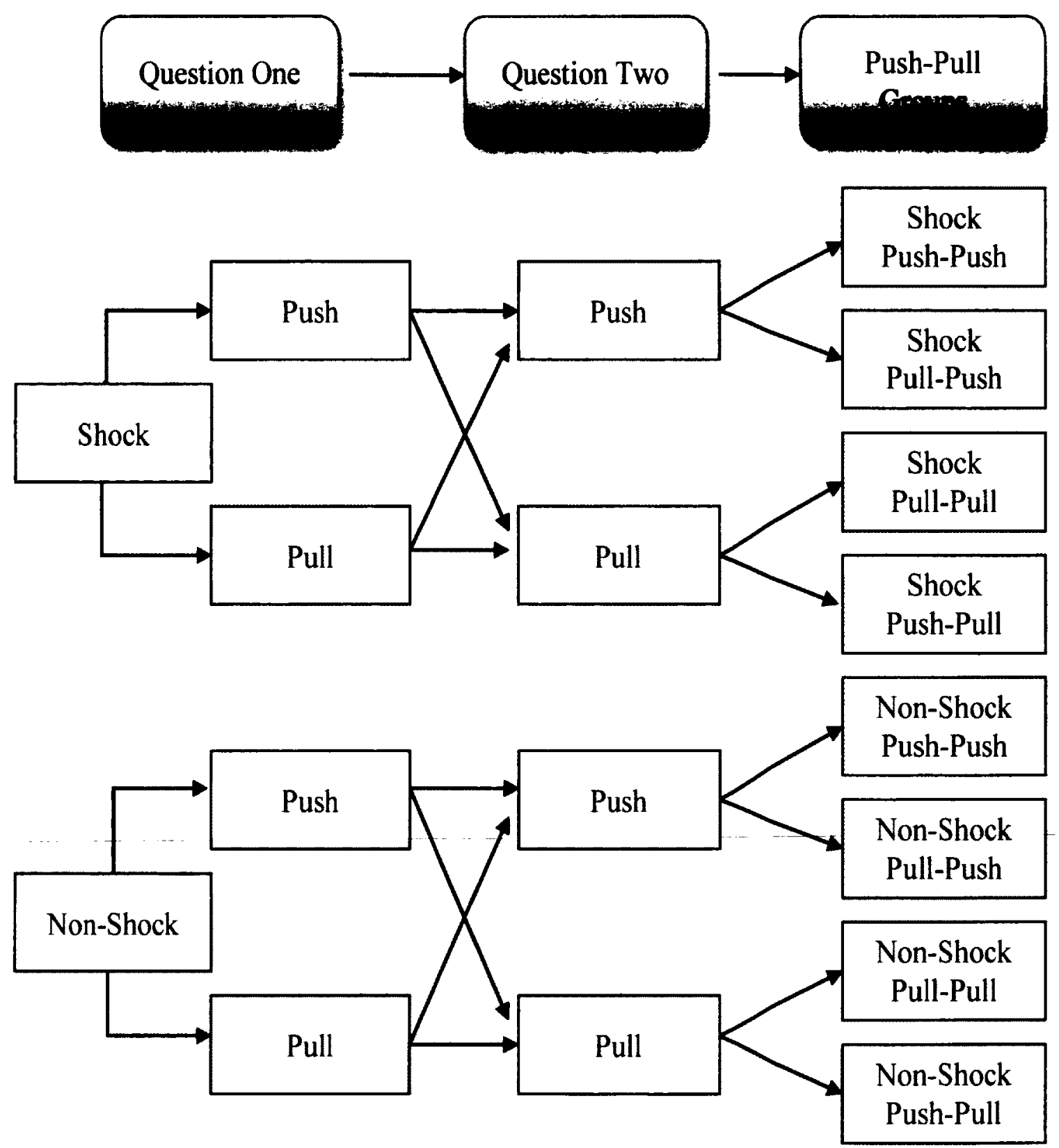

Figure 2. The push-pull quitting sequence. 
Shock - Pull/Push Group. Respondents in this group identified a shock pull event as first prompting them to consider quitting and a push factor as the actual reason for quitting. For example, when a military member learned she was pregnant (pull), she began to consider quitting. After some deliberation, however, she decided not to quit. Then prior to having the baby, the military introduced new rules severely limiting the number of days available for maternity leave. These amendments to the leave policy, then made her to decide to quit (push).

Shock - Pull/Pull Group. Respondents in this group identified a shock pull event as first prompting them to consider quitting and a pull factor as the actual reason for quitting. For example, a military member noticed a job posting in an area they were very qualified in. The job listing prompted the member to consider quitting (pull). After some deliberation, the member decided to apply for the job advertisement. After going through the hiring process, the member was offered the job (pull). As the job offer was very appealing the member decided to quit.

Shock - Push/Pull Group. Respondents in this group identified a shock push event as first prompting them to consider quitting. Respondents then identified a pull factor as the actual reason for quitting. For example, a military member received notice that the department was making changes to the pension policy (push). The changes were not drastic; however, they caused the member to consider quitting. As a result of the job changes, the military member explored other job possibilities. Upon receipt of a very 
appealing job opportunity the member decided to quit (pull).

Non-shock - Push/Push Group. Respondents in this group identified a nonshock push event as first prompting them to consider quitting. Respondents then identified a push factor as the actual reason for quitting. For example, over a period of time a military member became frustrated with a perceived lack of leadership within their unit (push), which prompted the member to consider quitting. However, the member only decided to actually quit after being denied a posting to be closer to their family ${ }^{5}$ (push).

Non-shock - Pull/Push Group. Respondents in this group identified a non-shock pull event as first prompting them to consider quitting. Respondents then identified a push factor as the actual reason for quitting. For example, a military member started to feel he/she wanted to spend more time with their family (pull). The desire to spend more time with the family prompted the member to look for another less demanding job. After a few months the member received a deployment notice (push). Not wanting to be away from his or her family, the member decided to quit.

Non-shock - Pull/Pull Group. Respondents in this group identified a non-shock

\footnotetext{
${ }^{5}$ Recall that a shock or non-shock sequence is determined by the event that prompts the member to consider quitting (Question One). Although posting seems like it is a shock event, because the sequence began with a non-shock event, the entire sequence is considered non-shock. The posting theme is still considered a push factor.
} 
pull event as prompting them to consider quitting. Respondents then identified a pull factor as the actual reason for quitting. For example, concerns over the high cost of day care prompted a military member to consider quitting and staying home to raise the children (pull). Although the member was very happy within the military, the member finally decided that staying home to raise his or her children was more important, thus the member decided to quit (pull).

Non-shock - Push/Pull Group. Respondents in this group identified a nonshock push event as prompting them to consider quitting. Respondents then identified a pull factor as the actual reason for quitting. For example, after returning from Afghanistan, a soldier became very bored with the daily life in garrison (push), and the boredom prompted the soldier to consider quitting. After submitting a resume to several companies, receipt of a job offer (pull) encouraged the soldier to quit.

In summary, for each of the two open-ended questions, participants' responses were categorized as falling into one of four groups: (a) shock-push factors, (b), shock pull factors, (c) non-shock - push factors and (d) non - shock pull factors. Moreover, both the shock group (push and pull factors) and non-shock group of responses were explored for themes specific to Canadian Forces members' initial thoughts and final decisions to leave the military.

Intercoder reliability. The process for generating intercoder reliability in this study followed guidelines provided by Hruschka et al. (2004). The initial step consisted 
of creating a codebook developed from the initial reading of participants' responses to the question asking what first prompted them to think about leaving the CF and the question asking what finally made them decide to leave the CF. Once initial themes were identified, each was explicitly defined. The primary coder then coded all of the responses as involving either shock or non-shock and as either push or pull factors. Finally, the responses were coded into themes reflecting what prompted military members' initial thought of leaving the $\mathrm{CF}$ and what made them finally decide to leave the Canadian Forces.

To ensure reliability of coding, a second coder was utilized. In a training session the second coder was familiarized with military-specific terms, given the definitions of, common acronyms and instructed on how to code responses containing multiple themes. When responses addressed more than one theme, and a specific theme was not identified as prompting initial thoughts of quitting or the primary reason for deciding to quit, the theme that was provided first was coded as the member's intended response.

After training, the second coder was provided with a copy of the codebook listing the themes and their definitions of the coded themes and asked to independently code a random sample of $20 \%$ of the responses. Cohen's Kappa, a measure of interrater reliability, was then calculated for the following responses: shock/non-shock, initial thought push/pull, final decision push/pull, initial thought themes, and final decision themes. For the five items that were coded (see Table 1), the values of Kappa ranged 
from 0.88 to $0.95, p<.001$. The second coder then coded a random $50 \%$ of the sample. Of the five groups of themes coded (see Table 1), the lowest intercoder reliability was found to be, Kappa $=0.91(p<.001), 95 \% \mathrm{CI}(0.890,0.937)$. Based on discussion between the two coders, the codebook was modified slightly, reducing the number of themes by combining them when appropriate.

The remaining data set was then independently coded by the second coder. Of the five groups of themes that were rated (see Table 1), the lowest intercoder reliability was found to be Kappa $=0.93(p<.001), 95 \%$ CI $(0.911,0.943)$. Areas where discrepancies existed were discussed and final coding decisions were agreed upon by both coders.

Thematic analysis. Overall, the length of military members' responses to the qualitative questions varied from very succinct to very verbose. The average length of responses to the question regarding their initial thoughts of leaving was 42 words $(S D=83.61$, range $=$ $1-1,577$ words). The majority of these responses consisted of one theme, $(73 \%, n=$ $859)$, followed by two themes $(\sim 18 \%, n=220)$, and three or more themes $(\sim 9 \%, n=$ 100). In response to the question regarding their final decision to leave, military members wrote an average of 22 words $(S D=32.39$, range $=1-352$ words $)$. 
Table 1 .

Values of Cohen's Kappa for shock/non-shock, initial thoughts push/pull, final decision push/pull, initial thoughts themes and final decision themes

\begin{tabular}{lcccc}
\hline \multicolumn{1}{c}{ Coding Item } & $n$ & $20 \%$ & $50 \%$ & $100 \%$ \\
\hline (1) Shock/non-shock & 1179 & $.947^{*}$ & $.955^{*}$ & $.954^{*}$ \\
(2) Initial thoughts - push/pull & 1179 & $.927^{*}$ & $.948^{*}$ & $.949^{*}$ \\
(3) Initial thoughts - themes & 1179 & $.913^{*}$ & $.927^{*}$ & $.927^{*}$ \\
(4) Final decision - push/pull & 1179 & $.928^{*}$ & $.935^{*}$ & $.951^{*}$ \\
(5) Final decision - themes & 1179 & $.885^{*}$ & $.914^{*}$ & $.931^{*}$ \\
\hline * $p=<.001$ & & &
\end{tabular}

Again, most of these the responses consisted of only one theme for quitting, $(84 \%, n=$ $944)$, while $13 \%$ of the responses $(n=160)$ involved two themes and $2 \%(n=25)$ of the respondents described 3 or more reasons for quitting. To aid readability and minimize reader distraction, when quoting participant's responses, spelling errors were corrected. No other changes to the data were made ${ }^{6}$.

${ }^{6}$ No changes to original data were made. 
Shock/Non-shock. A shock event was identified in $49.8 \%(n=587)$ of all quit decisions. Again, for the purposes of this study, a shock was defined as a specific event that causes an employee to reflect on their current situation and to engage in deliberations about voluntarily leaving the organization. The shock could be expected or unexpected; surprise is not an essential element. A shock may be considered positive, negative, or neutral.

Push/Pull factors. While exploring the nature of factors identified as shocks in Question One (Table 2 shows complete response frequency and percent), push factors accounted for $62.7 \%(n=739)$ of the reasons military members were first prompted to think about leaving the Canadian Forces, while pull factors accounted for $37.3 \%(n=$ 440 ) of the reasons identified. In Question Two, push factors accounted for $49.0 \%(n=$ 578) of the reasons military members finally decided to quit the Canadian Forces, while pull factors accounted for $51.0 \%(n=601)$ of the reasons identified.

Themes. Responses were analysed using the thematic analysis procedure described by Braun and Clarke (2006). Responses to the question regarding initial thoughts of quitting and final decision to quit were analysed separately and the responses were grouped by Shock and Push/Pull factors. Figure 3 provides a thematic map of the overall shock, push/pull and theme process. In total, 23 themes (see Appendices $\mathrm{C}$ and D) were identified and spread across the following eight groups: 
Table 2.

Frequency of shock/non-shock, push/pull factor and percent of sample

\begin{tabular}{ccccc}
\hline & $\begin{array}{c}\text { Initial } \\
\text { thoughts } \\
n\end{array}$ & $\%$ & $\begin{array}{c}\text { Final } \\
\text { decisions } \\
n\end{array}$ & $\%$ \\
Shock & & & & \\
Push & 337 & 28.6 & 248 & 21.0 \\
Pull & 250 & 21.2 & 339 & 28.8 \\
Non-Shock & & & & \\
\hline Push & & & & \\
Pull & 402 & 34.1 & 330 & 28.0 \\
\hline
\end{tabular}

Causes of Initial thoughts of quitting: Shock - Push Factors. Shock-induced push factors include factors that contain a distinguishable event that caused an employee to deliberate about quitting an organization. Push factors are factors within an organization's control. Four main shock-push factor themes were identified, including: posting (relocations) $(n=193,16.4 \%)$, career management $(n=63,5.3 \%)$, health/fitness $(n=38,3.2 \%)$, and operational tempo/deployment $(n=32,2.7 \%)$. 


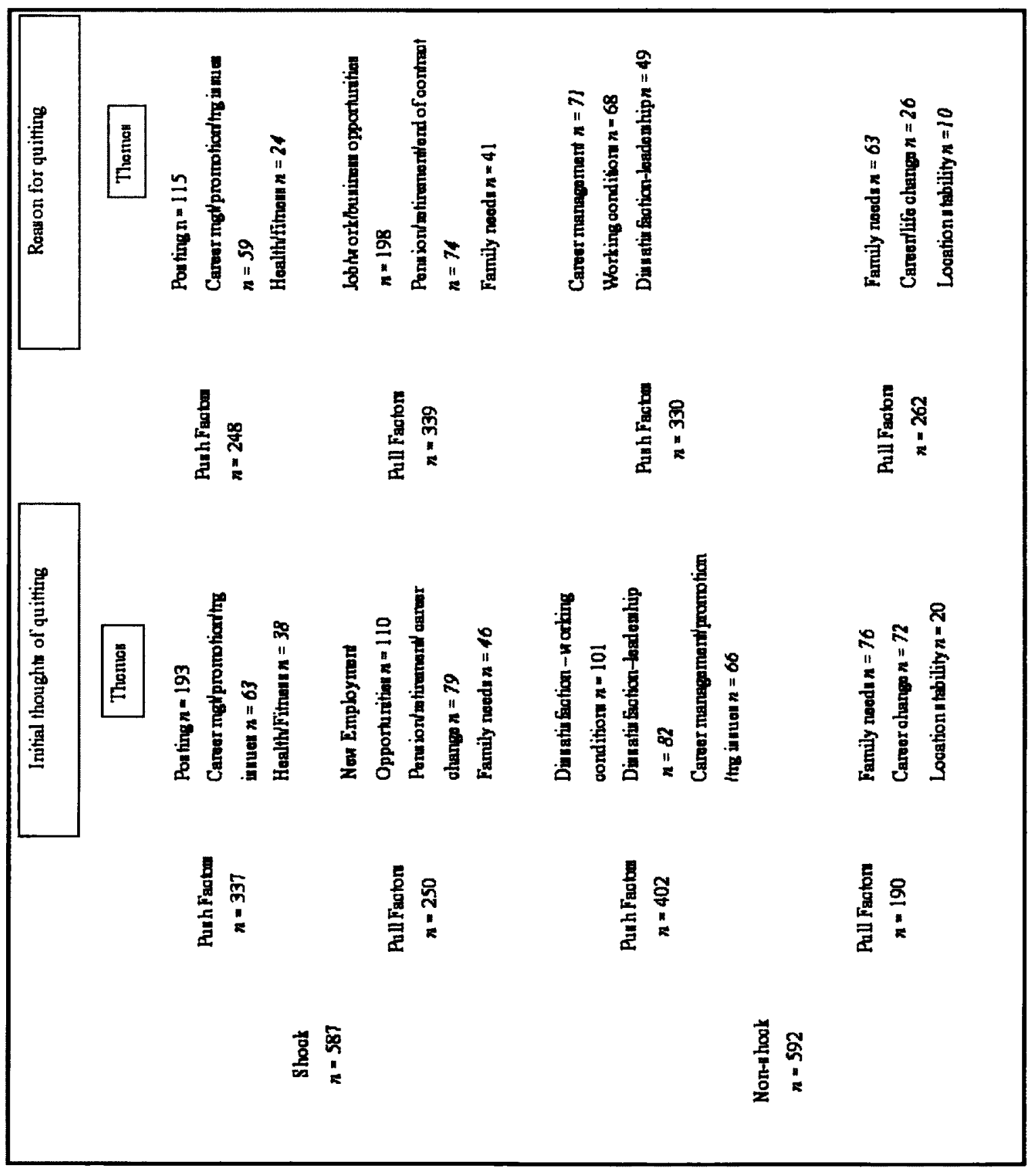

Figure 3. Thematic map of the overall quitting sequence. 
Although military members enrol in the Canadian Forces with the understanding that postings are common, postings were the most frequently mentioned reason for initial thoughts of quitting. Military members expressed different concerns about posting. In some instances an excessive number of moves was identified: "Transferts beaucoup trop frequents;", and "too many short postings, last three were 2 years each;" while in other situations a denial of a posting request was identified: "Inability to get a posting to assist parents with failing health." However the most widely commented on aspect of posting was the effect of a posting or potential posting on the family:

Family does not want to move anymore.

This would be the fourth geographical move in seven years for our family.

Once I was posted and couldn't be accommodated to allow my children to complete high school.

My children are in Grade 10 and Grade 6. My spouse was a child of a retired Reg Force member and with 14 moves in her life by age 42 , it was time to consider settling down in one area.

I did my time in Edmonton, wished to move back to Ontario, but was refused.

There was a good possibility that I was going to be posted out of the area after 6 yrs in Greenwood, even though other personnel of the same rank had been in Greenwood far longer $(10,13,16 \mathrm{yrs})$.

\footnotetext{
${ }^{7}$ English translation: Too frequent transfers.
} 
The second most common theme after posting was career management. Military members expressed experiencing initial thoughts of quitting after frustrating experiences during training or with their career management. Typical concerns included occupational transfers, promotion or training issues, and frustration with their career manager. Some typical comments were: "When my career manager informed me that a sailors place is at sea, and that's where I need to be! After fourteen years at sea and ninety percent of that sailing on submarines I definitely did not agree with his statement;" "When I realized that there was no way of getting a trade transfer out of the Sig Op trade;" and

Due to a course failure, I required a reassignment to another trade and also due to my CEOTP [Continuing Education Officer Training Plan], I was very limited to available open trades. My choices included Infantry, Artillery, Cbt Eng [combat engineer], NCM [Non-commissioned member] or Reserve. As a former reserve infantry Sergeant with 14 years experience, I still wanted to remain in the Forces, however, those trades did not interest me. My choice to release was due to the trades that I was offered.

Health and fitness issues were cited by military members as the third most common reason for prompting thoughts of quitting. Comments included: "I had injuries that continued to get worse as my training progressed. I decided that it was best if I left the military before my injuries became very serious and permanent;" and "I could no longer pass the express test, i.e. shuttle run." Another member stated, "hurting my back for a second time prompted me to realise my back was not fit for the infantry, to change 
trades I must VOR [voluntary occupational reassignment]," while another wrote, "Express Test at this stage in my life I did not want to take up jogging and being able to retire made the decision easy."

There were departing members who reported experiencing initial thoughts about quitting related to operational tempo and deployment issues. Some respondents described the operational tempo as too high: "Operational tempo, back to back tours in Afghanistan." and "I had a choice of deployment or get out." In other instances it was the lack of deployments that prompted military members to consider quitting. In this regard one member wrote, "[I] was not offered a second deployment from my unit."

Causes of Initial Thought of Quitting: Shock - Pull Factors. Pull factors are factors considered to be outside of an organization's control. Three main shock-pull factor themes were identified, specifically: new employment opportunities $(n=110$, $9.3 \%)$, pension/retirement/career change $(n=79,6.7 \%)$, and family needs $(n=46,7.7 \%)$. Canadian Forces members frequently cited receiving unsolicited job offers as a factor that first prompted them to think about quitting. Some comments were:

unsolicited job offer from the private sector.

A lucrative offer of employment from a large civilian organization.

Transfer to Primary Reserve, so I although I am leaving the Regular Force, am not really "leaving" the $\mathrm{CF}$.

Taking over family business. 
Received an attractive offer of employment from federal government, which was at a level that was higher than my current status within the CF.

Although many military members did not specify where the job opportunities were located, those who did often mentioned Canada's public service and positions in the military reserves.

Military members frequently cited pension benefits and retirement as reasons for initially thinking about quitting. The ability for members to retire from the Canadian Forces at a relatively young age and collect a pension while commencing a new career was often cited. One member stated: "20 years complete, want to start drawing pension." Another military member wrote: "Immediate annuity available and the feeling I had served long enough." For many military members the decision to leave the Canadian Forces coincided with the completion of their contract (terms of service). Many times military members stated that quitting at the end of their contract or when they were eligible for an immediate annuity was always the plan. However, in some instances, if military members felt their careers were going poorly, reaching the end of their contract prompted some members to consider quitting:

Contract was expiring. Didn't want to deal with the political jargon anymore. Broken promises, false intentions, people selected for leadership courses were extremely below capabilities to lead in a lot of instances. 
Promised time off and never received it (unit level), after long deployments and field ex's less than satisfactory family time compensated.

\section{Causes of Initial Thought of Quitting: Non-Shock - Push Factors.}

While shocks are distinguishable events that prompt employees to consider quitting, non-shock factors typically evolve over time and consist of a growing dissatisfaction with different aspects of employees' job or career that eventually prompt them to consider quitting. As push factors, these factors are typically within the organization's ability to control. Three main non-shock push factor themes emerged, specifically dissatisfaction with working conditions $(n=101,8.6 \%)$, dissatisfaction with leadership $(n=82,7.0 \%)$, and career management/promotion/training issues $(n=66$, $5.6 \%)$.

The Canadian Forces encompasses a wide array of occupations, each with different opportunities and challenges. Many Canadians are drawn to the Canadian Forces as they are seeking out new adventures and demanding challenges. During Canada's participation in Afghanistan, interest in combat arms ${ }^{8}$ occupations increased considerably. However, as combat operations decreased and operational tempo slowed, the opportunity to aggressively train for war and deploy overseas decreased. The slowed

\footnotetext{
${ }^{8}$ Combat Arms occupations are typically considered to consist of: infantry, artillery, armoured, and field engineer. During military operations (war fighting) these occupations are directly involved in the conflict.
} 
tempo, increased time in garrison, and perceived lack of opportunities was cited by some as an initial reason to consider quitting. Some participants expressed this as follows:

Felt that I wasn't being challenged and provided an opportunity to grow and develop.

Lack of significant clinical roles at the senior officer level.

The monotony of garrison life kills my soul. I think I can do more.

After coming back from Afghanistan I just didn't enjoy doing my job as much. All the training prior to Afghanistan was exciting and new. Once I came back, training for Afghanistan was a lot less enjoyable and I hated doing it all over again. I enjoy fast paced challenging work. I enjoy working with motivated people who can make decisions and take risks. As a junior field officer this was fulfilled, especially while on deployment. However, as I progressed away from the field work and the soldiers my job satisfaction diminished greatly. I see that much of my future would be spent as a staff officer in a top heavy organization. I do not enjoy bureaucracy and risk averse organizations. I do not want to spend the majority of my career in a government cubicle.

Some military members cited dissatisfaction with leadership (non-shock push) as a factor that first prompted them to consider quitting. Military members often cited a general dissatisfaction with officers' senior leadership as prompting their thoughts of leaving. One wrote: "The disregard of the troops' morale and lifestyle by officers intent of furthering their own careers.", while others cited their entire chain of command or 
immediate supervisor: "The poor treatment received from supervisors." Another member stated:

The disorganized gong show that constantly goes on due to young officers that only care about leaving their stamp on the unit. Bitter old dinosaurs that make your life hell just for the sake of it. One minded people that don't like to think outside of the box and it's always a "my way or the highway" attitude. My job (paratrooper) has the potential to be a great fun experience but it's always been the people that have ruined it for me.

another wrote:

The incompetence of command of a direct superior in Afghanistan. The poor treatment of other soldiers and the way battalion treats people. These are fundamentals that won't change no matter what. Also I aspire to do more than an enlisted man in the Canadian infantry.

Career management issues were cited by some military members as prompting them to first consider quitting the Canadian Forces. One member wrote, "Mismanagement of my career combined with failed attempt to further my education while still being employed in the CF." Another noted, "The career managers inability or lack of desire to match my skills and abilities to job opportunities. This created a lack of challenge and I became bored in my job." In some instances a perceived lack of promotion opportunities caused them to consider quitting, "Career advancement unlikely regardless of performance." Military members also noted concerns over training issues as the issue that prompted them to first consider leaving: 
Forced to follow combat arms trainings that don't have anything to do with my trade. i.e. CAP [Common Army Phase] Infantry and Combat Engineers training phase 3 even if I chose Airfield Engineers. 2 Totally useless and unprofessional CAP BMOQ-L [Basic Military Officer Qualification - Land] training in Gagetown. Everything I had to go through during CAP training was just a bad draft copy of my BMOQ-L in Saint-Jean-sur-Richelieu. The difference was that in Saint-Jean, the instructors were very professional and the teaching programs were very good and complete. During CAP training there was no training at all, just yelling and cocking.

Having to spend excessive time in one version or other of basic training.

The amount of time it took to receive my training (over a year). The sexist and racist culture of the units and leaders I have served for. The old equipment and poor training (unlike the advertised world-class training and state-of-the-art equipment).

Causes of Initial Thought of Quitting: Non-Shock - Pull factors. Typically, non-shock pull factors evolve over time and involve situations beyond the military's control. Two main non-shock pull factor themes emerged: family needs $(n=76,6.4 \%)$, and career/life change $(n=72,6.1 \%)$.

Taking care of family and/or putting family members first were often identified as factors that first prompted military members to consider quitting the Canadian Forces. Family considerations mainly revolved around immediate family members (spouse, children); however, coping with health concerns for aging parents and starting a family were also cited, as seen below: 
I wanted to take care of my 3 young kids.

I have two little boys at home who need their Mommy full time.

Family problem back at home.

My spouse's happiness, wish to return to his home country of New Zealand.

I have started a new family, and as family friendly as todays CF is a soldier and his family have to make great sacrifices. I had a difficult childhood where my family fell apart when I was young. In my life I will never put work before my family and at times the military has no choice, therefore I chose to leave instead of giving the army my second best.

Family situation, wanting to be closer to my mother who is faced with being alone.

Apart from family related issues, military members also cited a desire for career and life changes as prompting them to consider quitting. In general, military members stated they were looking to try something different. One member stated, "Just wanted to try something new." The majority of responses were neutral in terms of feelings toward the Canadian Forces, with military members simply expressing their desire to try new things. Some examples were: 
Try something different.

Desire to complete a University Education.

During my undergraduate studies at RMC, I developed a passion for engineering. I determined that the opportunities available to me to pursue a career conducting engineering analyses in the $\mathrm{CF}$ were very limited, and began looking elsewhere.

\section{Causes of final decision to leave the Canadian Forces: Shock - Push Factors.}

In response to the question what finally made you decide to leave the $\mathrm{CF}$, three main push factor themes emerged within the shock group of responses, they were: posting ( $n=$ $115,9.8 \%)$, career management/promotion/training issues $(n=59,5.0 \%)$, and health/fitness issues $(n=24,2.0 \%)$.

The importance that military members place on where they live is clearly evident in the reasons they gave for their final decision to quit. Just as posting was the most common reason for military members' initial thoughts of quitting the Canadian Forces, posting was also the most frequently cited reason for their eventual decision to quit. In many instances, after being told they were being posted, military members engaged their career managers in an attempt to have the posting changed or cancelled. However, once their request was denied, they quit. As in Question One, denied requests for posting to specific locations was a factor in many military members' decision to quit. In this regard some military members said:

4 months from the receipt of my posting message and after continued efforts to find a solution that would be considered by the Career Manager. I waited until 
the last possible moment in order to assist the Unit which is currently severely short-handed and supporting Combat Ops [operations] and Trg [training].

The career shop didn't care about me and my family situation. I know they have positions to fill, but they don't seem to realise that they are filling those positions with HUMAN BEINGS.

Being on an $\mathrm{IR}^{9}$ posting for an extended period of time; and being told by the $\mathrm{CM}$ [career manager] that I will NOT be posted back to the base I'm on IR from.

When my spouse's CM refused to reconsider his decision to post him to a Priority 6 position in Toronto, vice leaving him in Petawawa and posting him into the vacant Priority 6 position there.

No posting and no hope of a posting in the future. I was told I would not be posted to New Brunswick and would never be! There are positions there for my occupation.

I approached the Senior Sup Tech [Supply Technician] ref the posting, explaining why I didn't wish to take it. I was informed that the posting was going to happen. I thought about a couple of more days, then concluded that the new posting was not how I saw myself finishing my career and submitted my release.

I finally made my decision of leaving after talking over with my spouse. We have been establish for quite some time here and now my spouse is very happy where she works and moving this time around would mean, she would have to start over

\footnotetext{
${ }^{9}$ Imposed Restriction Status (IR) - In the Canadian Forces imposed restriction status occurs when a military member is relocated without their family. Imposed restriction status is requested by the military member for a temporary period of time. Upon completion of imposed restriction status the military member's family is then relocated with the member.
} 
again. She would lose her seniority due to the fact the company she works for is provincial and strictly here in $\mathrm{BC}$. As well my son education is here at $\mathrm{U}$ Vic and he has one year left. If we were to move and leave him behind that would put a strains on our finance as he would need to get accommodation and the cost of living is high in the region. Although I had elected to proceed on my posting on IR. After second thought and knowing how it is on IR since I did it in the past. Both my wife and I didn't like or wanted to really do this again.

Apart from concerns over posting, military members also cited career management/promotion/training issues/ and health/fitness issues as reasons for quitting. Because training is a very important factor for advancement in the Canadian Forces, the availability of training courses played a key role in some military members' decisions to quit. One member wrote: "Being bumped off of the next career crse [course] for someone junior." Others also commented on concerns they had with career management and training:

Ottawa did not give me an educational waiver/allow me to obtain a Master's while in the CF and therefore I could not apply to the trade which was open and red, neither could I apply to the trades which fit my degree because they were closed. With numerous letter of reference, a good record of work, and a desire to stay in the CF I fought hard to get my paperwork recognized at a higher level. career. The way they allowed personnel to pass crses [courses] when they should not have passed and when all the instructors agreed that they should not pass.

Another member's concern over career management was why he decided to quit, "A phrase by a sergeant, 'If you don't like it, you can pack up and get out." Disillusionment 
with promotion opportunities was also cited, with one member saying, "Promotion opportunities were lacking and I have ambition to do more." another stated, " No career progression planning for HR officers in the Log Branch and the now added age restrictions for promotion."

Recognizing that serving in the Canadian Forces is very physically demanding, other military members cited health concerns and injuries sustained while serving as their reasons for quitting. Members noted: "hurting my back for the second time" as the reason for deciding to quit, "getting injured on CAP [Common Army Phase]course in Gagetown, knowing that I will have to wait longer to finish CAP and even longer before getting on BIOC [Basic Infantry Officer Course]," and "Mandatory PT [Physical Training]." As a reason for quitting one member wrote, "Workplace stress, career and other health-related issues. The availability of defined, immediate assistance to resolve same."

Causes of final decision to leave the Canadian Forces: Shock-Pull Factors. Three main shock induced pull factors were identified in response to the question what finally made you decide to leave the CF, they were: job/business opportunities ( $n=198$, $16.8 \%)$, pension/retirement/end of contract $(n=74,6.3 \%)$, and family needs $(n=41$, $3.5 \%$ ). Job/business opportunities were the most frequently cited pull factor for quitting the Canadian Forces within this group of responses:

An opportunity came up within the private sector that I could not pass up. This opportunity would not have been there when I planned to retire (in 5 years) as I 
would have been out of my speciality field after this year and would not have been as qualified.

I was upset over a posting while I was deployed, after being told that I would not be posted. Once I received a good job offer, the decision was easy.

I was accepted as a Calgary Police Constable and my wife can seek advancing employment in Calgary.

A PS [Public Service] job offer that would take full advantage of my experience as well as the opportunity to stay in the NCR [National Capital Region].

I was offered an EX-02 position at PWGSC [Public Works Government Services Canada] in my preferred field (telecommunications).

Not totally leaving the CF. Winning a competition for a Class B Reserve job is what prompted me to retire from the Reg [Regular] force.

Military members' decisions to quit the Canadian Forces were also affected by the availability of an immediate annuity after 20 years of service. Pension/retirement/end of contract were commonly cited as the reason for quitting. In most instances the availability of a pension provided a gateway for many military members to leave the Forces. However, as per the CF attrition statistics (Otis \& Straver, 2008), attrition is very low between 15 and 20 years of service, perhaps because pensions are only received after 20 years of service. One member cited this fact as a reason for staying until completion of 20 years of service: "Reaching 20 years with eligibility for a pension. I really don't like my job and would have left a few years ago but it would have been stupid to quit before I got my pension eligibility." Other members wrote: 
Combination of factors. Primary the ability to draw an immediate annuity. This allows me to pursue other options in my life while still at a relatively young age. Secondary was the fact that I found work frustrating at times. The length of time to see changes happen was difficult at times.

With my 20 year mark approaching I was faced with the decision of whether to retire at the end of my IE [initial engagement] or continue into my IPS [indefinite period of service]. My husband and I discussed this at length and decided we want to put down roots in one place.

Family needs, including immediate family issues, were also cited as a reason for quitting. One member wrote: "I had my first child on the way, I wanted to see her before her third birthday." Another member noted "family medical emergency" as a reason for quitting.

\section{Causes of final decision to leave the Canadian Forces: Non-Shock-Push}

Factors. Three main push factor themes comprised the non-shock responses to the question what finally made you decide to leave the $\mathrm{CF}$, including career management/promotion/training issues $(n=71,6.0 \%)$, dissatisfaction with working conditions ( $n=68,5.8 \%)$, and lack of fit $(n=33,2.8 \%)$.

Dissatisfaction with the promotion system or the actions of the career manager was often cited. Moreover, not receiving training in a timely manner was a concern for new members of the Canadian Forces:

I was given 2 choices by the career manager and this one was suitable for me. 
Bad career management (five managers in five years), and inflexibility on new policy changes. I can only push my own career management goals if supported by the chain of command.

Continued inflexibility of the Career Manager.

After talking to the career manager.

The senior AES OP(s) [Airborne Electronic Sensor Operator] did not seem interested in insuring that $\mathrm{I}$ would be trained in a timely fashion.

Many examples of careerism and a PER [Personnel Evaluation Report] system that promotes such behavior. I believe that the current PER system forces an individual to compete in a system that promotes conformity to behaviors inconsistent with our current leadership manual. I have strong faith in the senior leadership of the CF to be able to produce such powerful and directing leadership manuals but we are not measured against it. The manuals are very well written and when the behaviors are practiced I believe they will produce outstanding results and the results must be measured from 360 degree feedback. Subordinates must have a say in who are demonstrating effective leadership in the per process.

Dissatisfaction with working conditions was also a frequently cited as a reason for quitting the Canadian Forces. As with all non-shock reasons, dissatisfaction with working conditions develops over time and is typically not attributable to one isolated incident. Recurring problems were commonly mentioned. As one technician stated, "Tired of the same problems. No parts to repair aircraft. No new equipment. CF making the same mistakes (re organizing) over and over." Another cited their general dissatisfaction with morale: "I finally got fed up with my poor work environment and the 
poor morale of my unit." A realization that the Canadian Forces lifestyle or specific occupation was not what they wanted resulted in some military members deciding to quit. In this regard two members wrote, "When I figure that the CF wasn't for me" and "Total lack of interest in the trade." Another member stated:

That I wasn't being challenged enough and not allowed to be challenged. I wanted a place that I would be learning every day and challenged in my profession. I was NOT challenged to the smallest degree, I was not allowed to challenge myself in any degree within my trade that I should have been. My trade was too boring.

Another member related, "I decided to wait it out to see if my interest and motivation would change towards my job and only my frustration grew so that is when I knew this job was not for me." Lastly a member summed up their feelings for wanting to quit, saying "Being trapped in a trade that I did not want to do."

\section{Causes of final decision to leave the Canadian Forces: Non-Shock-Pull}

Factors. Three main pull factor themes emerged within the non-shock responses to the question, what finally made you decide to leave the CF, including job opportunities ( $n=$ $107,9.1 \%)$, family needs ( $n=63,5.3 \%)$, and pension/retirement/end of contract $(n=48$, 4.1\%). As with the pull factors within the shock group of responses regarding initial thoughts of leaving, job opportunities was the most frequently mentioned non-shock pull factor. As demonstrated in the following quotes, Canadian Forces personnel's skills often make them an attractive target for recruiters from a wide spectrum of employers: 
Opportunity arose many times during my time in Alberta. High paying jobs for hard working people in the oil patch.

Job offer from dockyard for a civilian position.

Simply put, I was made an offer I can't refuse. My total income package will effectively double, my children's university will be more or less paid for, and my wife and I can continue to live in Europe for another ten or fifteen years. Additionally, I will not be faced with the prospect of a final posting in Canada where I would have to focus on finding a second career during an economic downturn and would therefore be driven to specific locations where we do not necessarily want to retire eventually.

I was offered a very good position doing the clinical work I like doing plus I would receive six weeks annual.

Military members cited a wide range of family related issues as reasons for quitting. In some instances members felt that service life was not compatible with raising a family. One female member stated: "I became pregnant, my priorities changed," while another member explained: "I decided I would rather be home with my children while they're young." In other instances a combination of factors experienced by the member while serving prompted them to make a decision between the Canadian Forces and their family: "After speaking with my CR Mgr [ career manager] \& hearing that he would not re-unite me with my family \& had another lengthy IR [imposed restriction] planned for me I put out resumes \& I had a job in 2 months.” Another member said, “ I had worked extremely hard to get certified as a marine engineer, put in all the extra hours, strived to 
be the top performer ever year only to get myself promoted out of the few shore postings we get. I am releasing 1 day short of 2 years at this posting to go back to sea away from my family for another 4 years....no thanks."

Pension/retirement/end of contract was also cited by some military members as reasons for deciding to leave, some examples noted were: "I had reached a point where I was entitled to a full pension and decided that it was time to start enjoying it." "Retirement - Time to move on.", "I was coming to the end of my IE and felt it was the right time to leave." Lastly one member summed up their feeling for finally deciding to quit by saying "I finally decided to leave after I'd completed (in my mind) my obligatory service to $443(\mathrm{MH})$ Sqn [Maritime Helicopter Squadron], eg: once my sailing time was complete and I completed a shore position tour."

To summarize, a shock event was identified in approximately $50 \%$ of military members' decisions to quit the Canadian Forces. Push factors accounted for $63 \%$ of the reasons that prompted military members to first think about quitting, while pull factors accounted for $37 \%$ of their initial thoughts of quitting. Military members cited pull factors $51 \%$ of the time as the actual reasons for quitting, while push factors accounted for $49 \%$ of the reasons they actually quit the Canadian Forces. In response to the question asking military members "What first prompted you to think about leaving the CF?" and the question "What finally made you decide to leave the CF?", posting was cited as the number one push factor reason for both questions. New 
employment/job/business opportunities were the most frequent pull factor reasons for initial thoughts of leaving and actual quitting. When a shock was identified as the reason for military members' first thoughts of quitting, a pull/pull quitting sequence was taken most often. When a non-shock reason was identified as the reason for military members' first thoughts of quitting, a push/push quitting sequence was taken most often.

Quantitative analyses. While a qualitative analysis was used to understand how quit decisions are made (i.e., existence and nature of shock events and nature of decisive factors that influenced Canadian Forces members in their decision to voluntarily leave the organization), a quantitative methodology was used to explore the speed and difficulty of the decision-making process. In this study the question: “After your first thoughts about leaving, how long did it take for you to make the final decision to leave the CF? ${ }^{11}$ " was used to explore the timeframe for the quit decision, after members' first thoughts about quitting. The "How difficult was it for you to make the decision to leave the CF?" question was used to explore whether the different groups (shock/non-shock, push/pull) experienced differences in how difficult it was to quit.

\footnotetext{
${ }^{11}$ Available responses to the question "After your first thoughts about leaving, how long did it take for you to make the final decision to leave the CF?", ranged from less than a month to more than 10 years ("don't know" was also a response option). Concerns over response options, specifically, how long an employee would realistically take to quit after their initial thoughts of quitting led me to cap the response time to a maximum of 5 years. As a result of this decision, 60 respondents who had indicated either don't know or more than 5 years were recoded as missing.
} 
Attempting to understand how years of service might affect the quitting process was accomplished by asking quitting members: "How many years have you served (Combined Regular and Reserve service)?" Understanding where Canadian Forces members are in their career when they quit may help to better understand the quitting process. In sum, the quantitative analyses were conducted to explore whether the shock and non-shock groups identified in the qualitative analysis differed on length and difficulty of the quit decision, and years of service at the time of quitting.

Expanding on Holt et al.'s (2007) study, which used a military sample consisting solely of officers, the quantitative analyses of this study also aimed to test whether noncommissioned members and officers differed in the time and difficulty of their quit decisions, and their years of service at the time of quitting. Finally, the eight push/pull groups were explored for differences in the time and difficulty of their quit decisions, and years of service at the time of the decision.

Shock/Non-shock. An independent-samples t-test was conducted to compare whether leavers who experienced a shock event took more or less time to quit the Canadian Forces after their first thoughts of quitting relative to leavers who did not experience a shock event. It was found that military members who experienced a shock event $(M=4.65, S D=5.26)$ took less time to quit the Canadian Forces after their first thoughts of quitting when compared to members who did not experience a shock event $(M=5.97, S D=5.54), t(1117)=-4.95, p<.001$, with an effect size of $r=.12$. 
An independent-samples t-test was further conducted to compare whether leavers who experienced a shock event found leaving the Canadian Forces more difficult than those who did not experience a shock event. The results of this analysis revealed that military members who experienced a shock event $(M=2.39, S D=.98)$ found quitting the Canadian Forces more difficult than members who did not experience a shock event $(M=2.51, S D=1.02)^{12}, t(1177)=-2.04, p=.042$, although the effect size was small $(r=$ $.07)$.

Further, an independent-samples t-test was conducted to explore differences in the years of service for members who experienced a shock event and those who did not experience a shock event when they quit the Canadian Forces. Results revealed that military members who experienced a shock event $(M=17.75, S D=10.80$ years $)$ had more total years of service in the Canadian Forces (Regular and Reserve Force service) when they left the military than members who did not experience a shock event $(M=$ $14.26, S D=10.81$ years $), t(1177)=5.54, p<.001$, with an effect size of $r=.15$

Officers/Non-commissioned members. As the only study of the unfolding model using a military sample that I was able to find (Holt et al., 2007) focused only on U.S. Air Force Officers, I conducted a comparison between officers and non-

\footnotetext{
${ }^{12}$ As noted previously, the difficulty of leave decision was measured on a 4-point Likert scale ranging from $1=$ very difficult to $4=$ very easy.
} 
commissioned members to examine the length of time it took to quit once the decision had been made, the difficulty of the quit decision, and the years of service at the time of quitting. As unequal sample sizes and distribution non-normality were present in the officer/non-commissioned member groups, non-parametric tests were utilized.

A Mann-Whitney $U$ test showed that officers (mean ranking $=658.73$ ) took more time to quit the Canadian Forces after their first thoughts of quitting than the noncommissioned members (mean ranking $=514.88), U(1119)=100130.5, z=-6.98, p<$ .001 , and the effect size was notable, $r=-.21$. Another Mann-Whitney $U$ test revealed that officers $($ mean ranking $=534.49)$ found the decision to quit the Canadian Forces more difficult than non-commissioned members (mean ranking $=615.89), U(1179)=$ 129934.50, $z=-3.97, p<.001$, with an effect size of $r=-.12$. Finally, a Mann-Whitney $U$ test revealed that officers (mean ranking $=659.68$ ) had more years of service when they left the Canadian Forces than non-commissioned members (mean ranking $=557.50$ ), $U(1179)=124620.50, z=-4.81, p<.001$, with an effect size of $r=-.14$.

Push/Pull groups ${ }^{13}$. As unequal sample sizes and distribution non-normality were present among all the shock, non-shock push/pull groups, non-parametric tests were utilized to examine for group differences in the length of time it took to quit once the decision had been made, the difficulty of the quit decision, and the years of service at the

\footnotetext{
${ }^{13}$ A description and example of each group was presented in the qualitative analysis section.
} 
time of quitting. Figures 4 and 5 provide an overview of the distribution of the shock and non-shock push/pull groups.

A Kruskal-Wallis test was conducted to evaluate median differences (see Table 3) among the eight shock/non-shock push/pull groups (Shock Push/Push, Shock Push/Pull, Shock Pull/Pull, Shock Pull/Push; and Non-Shock Push/Push, Non-Shock Push/Pull, Non-Shock Pull/Pull, Non-Shock Pull/Push) on how long it took respondents in these groups to leave the Canadian Forces after their first thoughts of quitting. The test was significant, $H(7)=34.15, p<.001$. Results showed that the time it took military members to quit the Canadian Forces after their initial thoughts of quitting was significantly affected by the nature and the sequence of the factors that triggered their initial thoughts of quitting and their final decision to quit. The shock Push-Pull group (mean ranking = 476.32) took the least amount of time to quit, in contrast, the non-shock Push-Pull group (mean ranking $=663.71)$ took the longest amount of time to quit ${ }^{14}$.

${ }^{14}$ Lower mean rank scores represent less time taken to quit. 


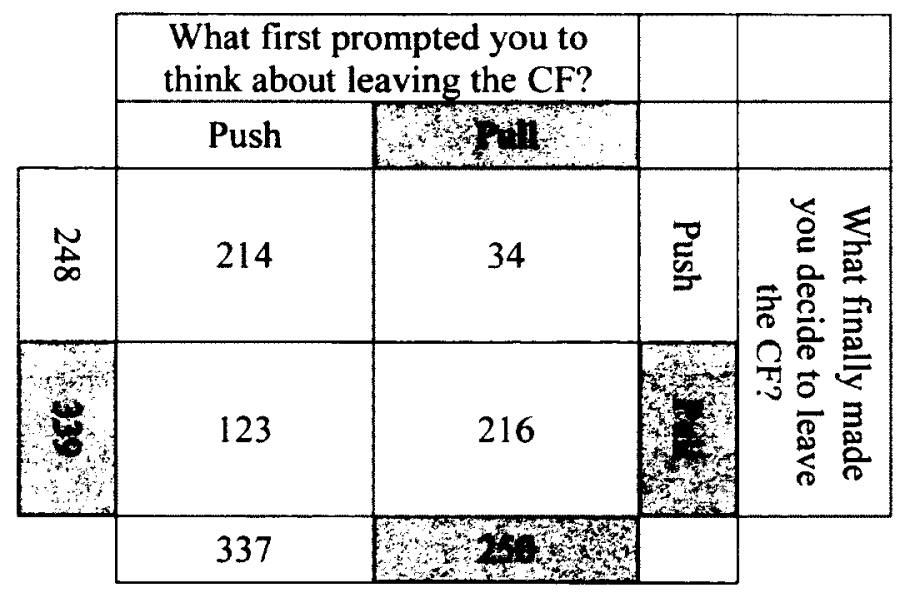

Figure 4. Shock - push/pull group frequencies responses to the questions "What first prompted you to think about leaving the CF?" and "What finally made you decide to leave the CF?"

\begin{tabular}{|c|c|c|c|c|}
\hline & \multicolumn{2}{|c|}{$\begin{array}{l}\text { What first prompted you to } \\
\text { think about leaving the CF? }\end{array}$} & & \\
\hline & Push & 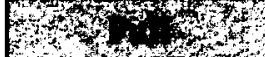 & & \\
\hline$\stackrel{w}{g}$ & 282 & 48 & $\begin{array}{l}\vec{D} \\
\stackrel{0}{5}\end{array}$ & 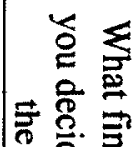 \\
\hline 8 & 120 & 142 & (6) & 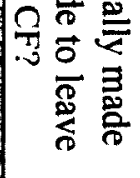 \\
\hline & 402 & 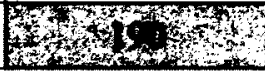 & & \\
\hline
\end{tabular}

Figure 5. Non-Shock - push/pull group frequencies responses to the questions "What first prompted you to think about leaving the CF?" and "What finally made you decide to leave the CF?" 
A Kruskal-Wallis test was conducted to evaluate median differences (see Table 3) among the eight shock/non-hock push/pull groups (Shock Push/Push, Shock Push/Pull, Shock Pull/Pull, Shock Pull/Push; and Non-Shock Push/Push, Non-Shock Push/Pull, Non-Shock Pull/Pull, Non-Shock Pull/Push) on median decision difficulty to quit the Canadian Forces. The test was significant, $H(7)=32.66, p<.001$. Results showed that the difficulty of the decision to quit the Canadian Forces was significantly affected by the sequence they used to quit the Canadian Forces. The shock Push-Push group (mean ranking $=510.98)$ found the decision to quit the most difficult, in contrast, the non-shock Push-Pull group (mean ranking $=692.06$ ) found the decision to quit the easiest ${ }^{16}$. Finally, a Kruskal-Wallis test was conducted to evaluate median differences (see Table 3) among the eight shock/non-shock push/pull groups (Shock Push/Push, Shock Push/Pull, Shock Pull/Pull, Shock Pull/Push; and Non-Shock Push/Push, Non-Shock Push/Pull, Non-Shock Pull/Pull, Non-Shock Pull/Push) to explore between group differences in years of service at the time of leaving the Canadian Forces. The test was significant, $H(7)=61.48, p<.001$.

\footnotetext{
${ }^{16}$ Lower mean rank scores represent increased difficulty
} 
Table 3.

Group size, mean rankings for shock and non-shock push/pull groups for questions 1, 2, and 3.

\begin{tabular}{lcccc}
\hline Groups & $n$ & $\begin{array}{c}\text { Mean } \\
\text { Ranking } \\
\text { Q1 }^{\mathrm{a}}\end{array}$ & $\begin{array}{c}\text { Mean } \\
\text { Ranking } \\
\mathrm{Q2}^{\mathrm{b}}\end{array}$ & $\begin{array}{c}\text { Mean } \\
\text { Ranking } \\
\mathrm{Q3}^{\mathrm{c}}\end{array}$ \\
\hline Shock & & & & \\
& & & & \\
(1) Push-Push & $(211)^{\mathrm{d}} 216$ & 515.36 & 510.98 & 578.78 \\
(2) Push-Pull & $(119)^{\mathrm{d}} 123$ & 580.07 & 561.33 & 696.34 \\
(3) Pull-Pull & $(205)^{\mathrm{d}} 216$ & 476.32 & 629.76 & 675.12 \\
(4) Pull-Push & $(029)^{\mathrm{d}} 031$ & 568.81 & 628.60 & 659.65 \\
Non-Shock & & & & \\
\hline & & & & \\
(1) Push-Push & $(269)^{\mathrm{d}} 280$ & 583.52 & 608.89 & 474.27 \\
(2) Push-Pull & $(115)^{\mathrm{d}} 121$ & 663.71 & 692.06 & 567.02 \\
(3) Pull-Pull & $(128)^{\mathrm{d}} 145$ & 597.79 & 564.33 & 621.80 \\
(4) Pull-Push & $(043)^{\mathrm{d}} 047$ & 579.51 & 523.91 & 576.67 \\
\hline
\end{tabular}

${ }^{\text {a }} \mathrm{Q} 1$ - After your first thought about leaving, how long did it take for you to make the final decision? Lower mean rank scores represent less time taken to quit.

${ }^{b} \mathrm{Q} 2$ - How difficult was it for you to make the decision? Lower mean rank scores represent increased difficulty.

${ }^{\mathrm{Q}} \mathrm{Q} 3$ - How many years have you served? (Combined Regular and Reserve Force)

${ }^{d}$ sample size for Q1 Higher mean rank scores represent more years of service at time of quitting. 
Results showed that military members' years of service in the Canadian Forces at their time of quitting were significantly affected by the nature of the quit decision and the sequence they used to quit the Canadian Forces. The shock Push-Pull group (mean ranking $=696.34$ ) had the most years of service at time when they quit, in contrast, the non-shock Push-Push group (mean ranking $=474.27$ ) had the least amount of years of service when they quit. ${ }^{18}$

In summary, the quantitative analyses revealed there were significant differences between quitters who experienced a shock and those who did not. Quitters who experienced a shock as part of their quitting process found quitting more difficult, took less time to quit after their initial thoughts of quitting and had more total years of service than quitters who did not experience a shock. Significant group differences were found between the eight push/pull groups. The Shock Pull/Pull group took the least amount of time to quit the Canadian Forces after their initial thoughts of quitting. The Shock Push/Push group found the decision to quit the Canadian Forces the most difficult. The Shock Push/Pull group had the most years of service at the time of quitting. Significant group differences were also found between officers and non-commissioned members. Officers found the decision to quit the Canadian Forces more difficult, they took more

\footnotetext{
${ }^{18}$ Higher mean rank scores represent more years of service at time to quitting.
} 
time to quit after their initial thoughts of quitting and had more years of service at their time of quitting than non-commissioned members.

\section{Discussion}

The purpose of the present study was to integrate content and process models of voluntary turnover in order to understand why and how the Canadian Forces members voluntarily leave the military. To help understand why (content) military personnel quit the Canadian Forces, a qualitative thematic analysis was conducted on participants' responses to two open ended questions: "What first prompted you to think about leaving the CF?" and "What finally made you decide to leave the CF?"

\section{Shocks}

Lee and Mitchell's (1991) unfolding model introduced the concept of shock into one's decision to quit. In the present study, shocks were identified in approximately $50 \%$ of the decisions to quit the Canadian Forces, which is consistent with Lee et al.'s (1996) findings where shocks accounted for $48 \%$ of the decisions to quit for nurses who voluntarily left their organizations. The prevalence of shocks in this study is lower than in Lee et al.'s (1999) follow up study, where $70 \%$ of accountants' decisions to quit their organization commenced with a shock event, in Holt et al.'s (2007) study, where it was found that $62 \%$ of military officers experienced a shock prior to quitting the United States Air Force, and in Holtom et al.'s study (2005) where it was found that $64 \%$ of individuals who quit from organizations left as a result of a shock. 
The lower prevalence of shock events in the current study when compared to other studies is worth further investigation. This lower prevalence could be related to methodological differences between the studies. In the present study the use of archival data limited my ability to ask participants if a shock event prompted their initial thoughts of quitting. During the thematic review of participants' qualitative responses to the question "What first prompted you to think about leaving the CF?" the responses were read and coded as either a shock or non-shock. In contrast, the previously noted studies (Lee et al. 1996, Lee et al. 1999, Holt et al. 2007, Holtom et al. 2005) included interviews and several questions in the questionnaires exploring whether a shock was experienced. Nevertheless, as suggested by Hom (2011), organizations might be better able to manage voluntary turnover if the organization is able to estimate the extent of shock-induced turnover. Therefore, further investigation in this area is warranted.

The results of this study show that terms of service and pension entitlement play a key role in Canadian Forces members' decisions to quit. Examination of reasons provided for quitting shows a substantial number of military personnel quit at the end of their terms of service. It is quite possible that providing set dates where quitting is possible may prime the member to dwell on these quit dates and actually quit at higher rates than had no terms of service been implemented.

The presence of shocks is also important from a decision-time point of view. In Lee et al. (1996) and Lee et al. (1999) the quitting process resulting from a shock event 
took less time than quitting that was initiated by job dissatisfaction alone. The present study found similar results. When a shock event prompted a military member's first thoughts of quitting, the time taken to finally decide to quit was significantly less than when a shock event was not experienced. These findings have practical implications. When shocks are experienced by military personnel, organizational leaders have less time to respond to members' concerns than when job/career dissatisfaction is experienced over a longer period of time. Given that half of the sample in this study did not experience a shock, a proactive focus on the factors contributing to dissatisfaction identified in the present study could be an efficient organizational intervention.

It is worth noting that when shocks were identified as prompting military members' initial thoughts of quitting, they were mostly of a push nature. That is, the shock events were related to factors within the organization's control, thus providing an opportunity to proactively address the internal factors that drive military members out. However, in the shock sequence, pull factors were predominant in military members' actual decision to quit, highlighting that military members are sought after by civilian employers.

\section{Push/Pull Groups}

The decision sequence to quit an organization described by Mobley's (1977) intermediate linkages model followed a linear path commencing with job dissatisfaction followed by thoughts of quitting, job search, and intention to quit, finally culminating in 
quitting. Lee and Mitchell's (1994) unfolding model expanded turnover theory by introducing additional paths to the quitting process. Moreover, they argued that life circumstances could intervene in a satisfied employee's life causing them to quit. They described these circumstances as shocks. Maertz and Campion (2004) combined process and content theories and concluded that specific motives for quitting were systematically related to certain processes.

To explore the decision-making sequence of quitting the Canadian Forces, the present study examined the nature of the factors that made departing members first think about leaving and then the factors that made them finally decide to quit. These factors were coded as push (i.e., within the control of the organization) or pull (i.e., external to the organization). Based on this classification, eight shock/non-shock, push/pull groups were established to explore sequence of factors in the decision-making process.

Examination of the individual push/pull paths revealed that when a shock event prompted initial thoughts of quitting, the pull/pull path $(n=216)$ and the push/push path $(n=214)$ were the two most prominent. When no shock event prompted initial thoughts of quitting, the push/push path $(n=282)$ was the most prevalent. It is worth noting that the path described by Mobley (1977) and Mobley et al. (1978), commencing with job dissatisfaction followed by thoughts of quitting, job search, intention to quit, and finally quitting, was not that prevalent. Indeed, in this study only $10 \%(n=120)$ of members followed this path of quitting, whereby they became dissatisfied, commenced a job search 
and quit once they received a job offer.

Overall, military members cited a substantially higher number of push factors $(n=$ 739) over pull factors ( $n=440$ ) as reasons that prompted their initial thoughts of quitting the Canadian Forces. However, they identified a more pull factors $(n=601)$ than push factors $(n=578)$ as primary reasons for actually quitting the Canadian Forces. These findings contribute to the understanding of the decision-making process to quit in a military organization and could provide grounds for developing interventions to proactively reduce voluntary turnover.

The results of the present study are also informative in understanding the length and difficulty of the quit decision-making process, in view of the factors that drive military members to leave. The shock pull/pull group took the least amount of time to quit after their first thoughts about quitting. The data shows that once a shock pull event takes place, the time from initial thoughts of quitting to actual quitting can be quite short. In this sample within 1 month of their initial thoughts of quitting, $50 \%$ of the shock pull/pull group had made their final decision to quit, and after 6 months approximately $80 \%$ had made the decision to quit. The very short time from initial thoughts of quitting to final decision to quit is an informative finding since the organization is not left with much time to react. The high prevalence of the pull/pull path points to a desirable workforce whose skills and competencies are sought after. As shown in the thematic analysis, military members are highly trained and sought after by both civilian and other 
government organizations.

Examination of the difficulty of the quit decision revealed that the shock push/push group found the decision to quit the Canadian Forces the most difficult and the non-shock push/pull group found the decision to quit the easiest. Sixty-three percent of the shock push/push group found the decision to quit very difficult or difficult while $60 \%$ of the non-shock push/pull group found the decision to quit the Canadian Forces easy or very easy. It is not surprising that this path provided the easiest decision when compared to the other push/pull groups. Once the members decided to start looking for alternative employment they had most likely already started to prepare themselves for leaving. In terms of years of service, the shock push/pull group had the highest number of years served at the time of quitting, while the non-shock push/push group had the lowest years of service, with $41 \%$ of the latter group quitting with 5 or less years of service. These findings show that once dissatisfaction with the organization starts, the member does not necessarily wait around until they find alternative employment. The findings suggest a confidence that departing members have in finding alternative employment once they leave the military.

\section{Themes}

The thematic analysis of respondents' answers to "What first prompted you to think about leaving the CF?" and "What finally made you decide to leave the CF?" revealed common themes that triggered members' initial thoughts of quitting and their 
final decision to leave. The use of military members' own words provided a deeper understanding of the various situations that they found themselves in while they were considering quitting and when they made the actual decision to quit. When a shock event prompted initial thoughts of quitting, posting (a push factor) was the most common reason identified. However, a review of the qualitative responses revealed that military members cited numerous reasons why posting prompted them to consider quitting.

In the majority of circumstances military members were unhappy about being moved from their current location. However, there were instances where military members quit because their request for a posting to be moved was denied.

In many circumstances, family reasons played a crucial role in the military member's deliberations about quitting. In some instances concerns for educational demands for teenage children in high school were cited. Military members expressed concerns over having to leave specific locations while their children were in their final years of high school or post-secondary education. Another commonly identified reason for not wanting to move was concern over a spouse's employment. In many instances spouses were employed in well-paying jobs that were not transferrable. Accepting a posting would force the spouse to quit and look for new employment.

Posting has been and may continue to be a necessary requirement for military service; however, family considerations may be worth taking into account by military career managers. The findings of the present study demonstrated that when forced to 
choose between relocation and family, family concerns are given top priority, resulting in the military member deciding to quit. It also seems that the military may need to move away from old methods where members either left or were encouraged to quit. One member immediately made the decision to quit when he was told: "If you don't like it, you can pack up and get out." The findings of this study show that military members are highly employable and sought after by civilian employers. Given this, encouraging them to quit rather than attempting to find solutions to their concerns is not in the military's best interests for retaining them. The many dimensions to why posting is commonly cited by military members as a reason for thinking about quitting or actually quitting is worthy of further investigation. Efforts directed at exploring ways to mitigate posting demands could potentially help reduce the impact of posting on attrition. Creation of geographical posting regions, whereby if a posting was necessary the member would be guaranteed a posting within that region may help alleviate a member's concern about posting. Moreover, additional training for career managers on how to deliver undesirable news, while not eliminating undesirable posting, may help member's better understand why a specific posting might be necessary.

New employment opportunities were identified as the primary pull factor reason in both "What first prompted you to think about leaving the CF?" and "What finally made you decide to leave the CF?" Unsolicited job offers were widely cited by military members as a reason that prompted them to consider quitting. It seems that civilian 
employers recognize that Canadian Forces personnel are highly trained, and by virtue of serving in the military, possess fundamental military values such as loyalty and integrity.

When no shock event was present, dissatisfaction with the working environment was cited as the primary push factor prompting military members to consider quitting, a finding in line with the findings within the content model. Family needs were identified as primary pull factor reason for thinking about quitting, again a finding that confirms previous research.

\section{Officers/Non-Commissioned Members}

Officers and non-commissioned members typically perform very different roles within the Canadian Forces. In civilian occupations, officers would typically be considered management, while non-commissioned members would make up the staff. With the exception of a few specific military occupations, officers are in leadership (management) positions, while the non-commissioned members carry out day-to-day duties. The inclusion of both officers and non-commissioned members in the sample of this study filled a gap in the current knowledge. Of key interest was whether officers and non-commissioned members would differ in how they quit the Canadian Forces.

Officers and non-commissioned members differed in the difficulty of their decision to leave the Canadian Forces, their years of service and the time it took them to finally decide to quit. After their first thoughts of quitting, officers took longer to make the final decision to quit. Of particular note is that approximately $27 \%(n=219)$ of non- 
commissioned members stated that, after their first thoughts of quitting, it took them less than one month to make their final decision to leave the Canadian Forces, while only $17 \%(n=65)$ of officers made their decision to quit in less than one month. Officers also found the decision to quit more difficult than non-commissioned members. Finally, at their time of quitting, officers had served more time in the Canadian Forces than noncommissioned members. More accumulated years of service for officers is likely attributable to terms of service requirements upon initial enrolment, with Officers being required to serve longer than non-commissioned members.

It is not clear why officers would find the decision more difficult and take longer to quit after their initial thoughts of quitting. However, terms of service may play a role in the process. Given that the initial engagement for officers is longer than that required for non-commissioned members, it could be feasible that officers engage in more deliberation and are more decisive about a career in the Canadian Forces than noncommissioned members. The difficulty of the leave decision may also be connected to the pre-enrolment decision making process. Given the educational requirements (undergraduate degree) for officers to join the Canadian Forces, officers may see their future in the Canadian Forces in a longer term. Further research on the quit decisionmaking process of officers and non-commissioned members could help shed light on the significant differences found in this study. 


\section{Limitations}

Several limitations were identified during the completion of this study. The use of archival data limited my ability to replicate Lee and Mitchell's (1994) unfolding model. However, as the Canadian Forces exit survey was designed, at least to some extent to explore how and why employees quit, the survey still provided a rich source of information about the quitting process. The survey was not specifically designed to measure shocks in the quit process but the use of the open-ended questions provided ample information to interpret whether a shock event was present.

During the analysis of the data, measurement problems were identified in the question asking military members how long it took them to quit after their first thoughts of quitting. Available response options were: less than 1 month, between $1-12$ months, 1 year and six months then between 2 and 10 years. No options were provided for members who fell between 1 year and six months and 2 years. Thus a span of 6 months was missing and not available as an option. It is anticipated that this measurement issue had very little effect on the outcome; however, it should be addressed for future surveys.

The present study was cross sectional in nature, therefore causal inferences cannot be made from the results. Only quitters were used in the study thus limiting the variance in turnover, differences between stayers and leavers were not examined. Another potential source of bias in the sample could be coming from the non-respondents, i.e., 
those serving members that left the Canadian Forces but did not complete the exit survey. Overall a response rate of approximately 20 percent was achieved.

The sample consisted of only military members from the Canadian Forces. As the Canadian Forces imposes a unique set of terms of service upon members, the results of this study may not be generalizable to a civilian population. Moreover, the Canadian Forces are one of the very few organizations in Canada that provide its members with an immediate annuity upon completion of military service. As was shown in the study a large proportion of military members quit the organization once they become eligible for the annuity.

Response options for the question, "After your first thoughts about leaving, how long did it take for you to make the final decision to leave the CF?" ranged from "less than a month" to "more than 10 years". As I felt it was unrealistic for a military member to take more than 5 years to quit after their first thought of quitting, only responses of 5 years or less were used, any responses greater than 5 years were deleted for that question. Future versions of the CF Exit survey should be modified to provide a more realistic time frame.

\section{Future Research and Conclusions}

The Canadian Forces exit survey provides for both quantitative and qualitative response options and thus allows exploring how and why Canadian Forces members quit. One of the questions examined in this study asked military members how difficult their 
decision to quit was. However, the survey also provided an opportunity for the members to express why their decision was either difficult or easy. Examination of their qualitative responses may provide further insight into their quit decision. Understanding the factors that made the quit decision either easy or hard would allow for a more in depth understanding of the quit decision-making process and its determinants.

Other areas that would be worth exploring might include the examination of differences between occupations. The Canadian Forces are made up of over 100 different occupations that range from uniquely military occupations such as infantry to occupations that are similar to their civilian equivalents, such as administrative clerk or medic. In many instances military jobs are very different from the closest civilian equivalents. However, some occupations such as nurses, doctors or pilots within the officer corps, and IT Tech or cooks on the non-commissioned member side are very closely aligned. Exploring whether differences exist between those occupations in terms of quit decision-making process and content may provide greater insight to who quits and who stays. With the abundance of research on nurse retention and attrition, comparisons between civilian and military nurses might provide some unique insight whether differences exist in the quitting reasons and sequence process.

Exploration for potential gender differences may provide some interesting results. Specifically, are there any differences in age between men and women when they quit the Canadian Forces and do men and women quit for similar or different reasons. Lastly, the 
use of longitudinal designs that address the limits of making causal inferences on the basis of cross-sectional data would be worth considering in future research, along with studying the leaving-related thought processes of both those who leave the CF and those who stay.

In conclusion, this study provided a picture of how and why military members quit the Canadian Forces. As with civilian organizations, a large portion of turnover is unavoidable (Hom, 2011). The presence of shock events in 50\% of military members' decisions to quit showed that unpredictable events can encourage satisfied members to quit. Unlike traditional turnover models, job dissatisfaction need not always be present.

The use of qualitative responses allowed for a richer insight into why Canadian Forces members quit. This deeper understanding may provide military leaders with the ability to design retention initiatives that better deal with military members' concerns. Moreover, this study provided insight into the quitting process (how). The process of push and pull factors showed that military members are highly employable outside of the Canadian Forces and routinely targeted by civilian organizations. 


\section{References}

ADM (HR-Mil) Instruction 05/05: The New CF Regular Force Terms of Service. (1 April 2005). Retrieved from Defence Information Network website (Not accessible outside of Defence Wide Area Network).

Ajzen, I. (1985). From intentions to actions: A theory of planned behavior. In J. Kuhl, \& J. Beckmann (Eds.), Springer series in social psychology (pp. 11-39). Berlin: Springer.

Ajzen, 1. (1991). The theory of planned behavior. Organizational Behavior and Human Decision Processes, 50, 179-211. doi: 10.1016/0749-5978(91)90020-T

Beach, L.R., \& Mitchell, T.R. (1987). Image theory: Principles, goals, and plans in decision making. Acta Psychologica, 66, 201-220. doi: 10.1016/00016918(87)90034-5

Braun, V., \& Clarke, V. (2006). Using thematic analysis in psychology. Qualitative Research in Psychology, 3, 77-101. doi: 10.1191/1478088706qp063oa

Carsten, J. M., \& Spector, P.E. (1987). Unemployment, job satisfaction, and employee turnover: A meta-analytic test of the muchinsky model. Journal of Applied Psychology, 72, 374-381. doi: 10.1037/0021-9010.72.3.374

Cotton, J. L., \& Tuttle, J. M. (1986). Employee turnover: A meta-analysis and review with implications for research. Academy of Management Review, 11, 55-70. doi: 10.5465/AMR.1986.4282625 
Dollar, C., \& Broach, D. (2006). Comparison of intent-to-leave with actual turnover within the FAA. FAA Final Report, DOT/FAA/AM-06/30. Office of Aerospace Medicine: Washington, DC. Retrieved from Defence Technical Information Center website: http://www.dtic.mil/cgi-bin/GetTRDoc?AD=ADA463866

Fishbein, M. (1967). Attitudes and the prediction of behavior. In M. Fishbein (Ed.), Readings in attitude theory and measurement. (pp. 477-492). New York: Wiley.

Fishbein, M., \& Ajzen, I. (1975). Belief, attitude, intention, and behavior. Reading, Mass.: Addison-Wesley.

Griffin, R. W., \& Bateman, T.S. (1986). Job satisfaction and organizational commitment. In C.L. Cooper and I. Robertson (Eds.), International review of industrial and organizational psychology (pp. 157-188). Chichester; New York: Wiley.

Griffeth, R. W., Hom, P. W., \& Gaertner, S. (2000).A meta-analysis of antecedents and correlates of employee turnover: Update, moderator tests, and research implications for the next millennium. Journal of Management, 26, 463-488. doi: $10.1177 / 014920630002600305$

Hinkin, T. R., \& Tracey, J.B. (2006). Development and use of a web-based tool to measure the costs of employee turnover: Preliminary findings. Ithaca, NY: Cornell University School of Hotel Administration Center for Hospitality Research. 
Holt, D.T., Rehg, M.T., Lin, J.H.S., \& Miller, J. (2007). An application of the unfolding model to explain turnover in a sample of military officers. Human Resource Management, 46, 35-49. doi: 10.1002/hrm.20144

Holtom, B.C., \& Inderrieden, E.J. (2006). Integrating the unfolding model and job embeddedness model to better understand voluntary turnover. Journal of Managerial Issues, 18, 435-452. Retrieved from http://web.ebscohost.com.proxy.library.carleton.ca/bsi/pdfviewer/pdfviewer?sid= e937bcc4-274a-4d29-a6d8-bd3837dd6dd8\%40sessionmer 13\&vid=4\&hid=25

Holtom, B.C., Mitchell, T.R., Lee, T.W., \& Eberly, M.B. (2008). Turnover and retention research: A glance at the past, a closer review of the present, and a venture into the future. The Academy of Management Annals, 2, 231-274. doi: $10.1080 / 19416520802211552$

Holtom, B.C., Mitchell, T.R., Lee, T.W., \& Inderrieden, E.J. (2005). Shocks as causes of turnover: What they are and how organizations can manage them. Human Resource Management, 44, 337-352. doi: 10.1002/hrm.20074

Hom. P.W. (2011). Organizational exit. In S. Zedeck (Ed.), APA handbook of industrial and organizational psychology (1st ed.). (pp. 325-375). Washington, DC: American Psychological Association. 
Hom, P.W., Caranikas-Walker, F., \& Prussia, G.E., \& Griffeth, R.W. (1992). A metaanalytical structural equations analysis of a model of employee turnover. Journal of Applied Psychology, 77, 890-909. doi: 10.1037/0021-9010.77.6.890

Hom, P.W., \& Griffeth, R.W. (1991). Structural equations modeling test of a turnover theory: Cross-sectional and longitudinal analyses. Journal of Applied Psychology, 76, 350-366. doi: $10.1037 / 0021-9010.76 .3 .350$

Hom, P. W., \& Griffeth, R. W. (1995). Employee turnover. Cincinnati, OH: SouthWestern.

Hulin, C.L. (1966b). Job satisfaction and turnover in a female clerical population. Journal of Applied Psychology, 50, 280-285. doi: 10.1037/h0023613

Hulin, C.L. (1968). Effects of changes in job-satisfaction levels on employee turnover. Journal of Applied Psychology, 52, 122-126. doi: 10.1037/h0025655

Hruschka, D.J., Schwartz, D, Cobb-St.John, D, Picone-Decaro, E, Jenkins, R.A. \& Carey, J.W. (2004). Reliability in coding open-ended data: Lessons learned from HIV behavioral research. Field Methods, 16, 307-331. doi: $10.1177 / 1525822 \times 04266540$

Lee, T.W., \& Mitchell, T.R. (1991). The unfolding effects of organizational commitment and anticipated job satisfaction on voluntary turnover. Motivation and Emotion, 15, 99-121. doi: 10.1007/BF00991478 
Lee, T.W., \& Mitchell, T.R. (1994). An alternative approach: The unfolding model of voluntary employee turnover. Academy of Management Review, 19, 51-89. doi: 10.5465/AMR.1994.9410122008

Lee, T.W., Mitchell, T.R., Holtom, B.C., McDaniel, L.S., \& Hill, J.W. (1999). The unfolding model of voluntary turnover: A replication and extension. Academy of Management Journal, 42, 450-462. doi: 10.2307/257015

Lee, T.W., Mitchell, T.R., Wise, L., \& Fireman, S. (1996). An unfolding model of voluntary employee turnover. Academy of Management Journal, 39, 5-36. doi: $10.2307 / 256629$

Locke, E.A. (1976). The nature and causes of job satisfaction. In M.D. Dunnette (Ed.), Handbook of industrial and organizational psychology, (pp. $1297-1349$. Chicago: Rand McNally.

Lytel, M.C., \& Drasgow, F. (2009). "Timely" methods": Examining turnover rates in the U.S. military. Military Psychology, 21, 334-350. doi:

\section{$10.1080 / 08995600802565693$}

Maertz, C. P., \& Campion, M. A. (1998). 25 years of voluntary turnover research: A review and critique. In C.L. Cooper \& I.T. Robertson (Eds.) International review of industrial and organizational psychology, (pp. 49-83). Chichester, UK: Wiley.

Maertz, C. P., \& Campion, M. A. (2004). Profiles in quitting: Integrating process and content turnover theory. Academy of Management Journal, 47, 566-582. 
doi: $10.2307 / 20159602$

March, J.G., \& Simon, H.A. (1958). Organizations. New York: Wiley.

Mathieu, J.E., \& Zajac, D.M. (1990). A review and meta-analysis of the antecedents, correlates, and consequences of organizational commitment. Psychological Bulletin, 108, 171-194. doi: 10.1037/0033-2909.108.2.171

McEvoy, G. M., \& Cascio, W. F. (1985). Strategies for reducing employee turnover: A meta-analysis. Journal of Applied Psychology, 70, 342-353. doi: 10.1037/00219010.70 .2 .342

Messervey, D.L., Howell, G.T., Gou, T., \& Yelle, M. (2011). 2010 Defence ethics survey report. DGMPRA TM 2011-037, Ottawa, Ontario: Director General Military Personnel Research \& Analysis Chief Military Personnel.

Meyer, J.P. (1997) Organizational commitment. In C.L. Cooper and I.T. Robertson (Eds.), International review of industrial and organizational psychology. (pp. 175 -228). Chichester: John Wiley \& Sons.

Meyer, J.P., \& Allen, N.J. (1991). A three-component conceptualization of organizational commitment. Human Resource Management Review. 1, 61-89. doi:

$10.1016 / 1053-4822(91) 90011-Z$

Mitchell, T.R., \& Beach, L.R. (1990). “...Do I love thee? Let me count...” Toward an understanding of intuitive and automatic decision making. Organizational 
Behavior and Human Decision Processes, 47, 1-20. doi: 10.1016/07495978(90)90044-A

Mitchell, T.R., Holtom, B.C., Lee, T.W., Sablynski, C.J. \& Erez, M. (2001). Why people stay: Using job embeddedness to predict voluntary turnover. Academy of Management Journal, 44, 1102-1121. doi: 10.2307/3069391

Mobley, W.H. (1977). Intermediate linkages in the relationship between job satisfaction and employee turnover. Journal of Applied Psychology, 62, 237-240. doi: $10.1037 / 0021-9010.62 .2 .237$

Mobley, W.H. (1982a). Employee turnover: Causes, consequences, and control. Reading, MT: Addison-Wesley.

Mobley, W.H., Griffeth, R.W., Hand, H.H., \& Meglino, B.M. (1979). Review and conceptual analysis of the employee turnover process. Psychological Bulletin, 86, 493-522. doi: 10.1037/0033-2909.86.3.493

Mowday, R.T., Porter, L.W., \& Steers, R.M. (1982). Employee-organization linkages: The psychology of commitment, absenteeism, and turnover. New York: Academic Press.

Otis, N., \& Straver, M. (2008). Review of attrition and retention research for the Canadian Forces. DRDC CORA TM 2008-030, Ottawa, Ontario: Director General Military Personnel Research \& Analysis Chief Military Personnel. 
Porter, L.W., \& Crampon, W.J., \& Smith, F.J. (1976). Organizational commitment and managerial turnover: A longitudinal study. Organizational Behavior and Human Performance, 15, 87-98. doi: 10.1016/0030-5073(76)90030-1

Porter, L.W., \& Steers, R.M. (1973). Organizational, work, and personal factors in employee turnover and absenteeism. Psychological Bulletin, 80, 151-176. doi: $10.1037 / \mathrm{h} 0034829$

Porter, L.W., Steers, R.M., Mowday, R.T., \& Boulian, P.V. (1974). Organizational commitment, job satisfaction, and turnover among psychiatric technicians. Journal of Applied Psychology, 59, 603-609. doi: 10.1037/h0037335

Steers, R.M., \& Mowday, R.T. (1981). Employee turnover and post-decision accommodation process. In L.L. Cummings \& B.M. Straw (Eds.), Research on organizational behavior, vol. 3, (pp. 237-249). Greenwich: JAI.

Tett, R.P., \& Meyer, J.P. (1993). Job satisfaction, organizational commitment, turnover intention, and turnover: Path analysis based on meta-analytic findings. Personnel Psychology, 46, 259-293. doi: 10.1111/j.1744-6570.1993.tb00874.x

Wanous, J. P., Poland, T.D., Premack, S.L., \& Davis, K.S. (1992). The effects of met expectations on newcomer attitudes and behaviors: A review and meta-analysis. Journal of Applied Psychology, 77, 288-297. doi: 10.1037/0021-9010.77.3.288 


\section{Appendices}

\section{Appendix A: Questions from the Canadian Forces Exit Survey 2008}

Why military members quit

Q1: What first prompted you to think about leaving the CF?

- Open ended - space provided for response

Q2: What finally made you decide to leave the CF?

- Open ended - space provided for response

\section{How military members quit}

Q1: After your first thoughts about leaving, how long did it take for you to make the final decision to leave the CF?

- 1: Don't know

- 2: Less than a month

- 3: between 1 and 12 months

- 4: 1 year \& 6 months

- 5: (between 2 and 10 years)

- 6: More than 10 years

Q2: How difficult was it for you to make the decision to leave the CF?

- 1: Very difficult

- 2: Difficult

- 3: Easy

- 4: Very Easy

\section{Years of military service}

Q1: How many years have you served? (Combined Regular and Reserve Force)

- 1: Less than one

- 2: years 


\section{Demographic Information}

What is your age?

- Under 20

- 20-25

- 26-30

- 31-35

- 36-40

- 41-45

- 46-50

- 51-55

- Over 55

What is your gender?

- Male

- Female

What is your first official language?

- English

- French 
Appendix B: Responses to "What first prompted you to think about leaving the CF?" - Complete set of themes identified

\begin{tabular}{|c|c|c|c|c|}
\hline & Frequency & Percent & Valid Percent & $\begin{array}{c}\text { Cumulative } \\
\text { Percent }\end{array}$ \\
\hline Shock Push - Posting & 193 & 16.4 & 16.4 & 16.4 \\
\hline $\begin{array}{l}\text { Shock Push - Operational } \\
\text { tempo/Deployment }\end{array}$ & 32 & 2.7 & 2.7 & 19.1 \\
\hline $\begin{array}{l}\text { Shock Push - Career } \\
\text { management/Promotion/Trai } \\
\text { ning issues }\end{array}$ & 63 & 5.3 & 5.3 & 24.4 \\
\hline $\begin{array}{l}\text { Shock Push - Health/Fitness } \\
\text { Issues }\end{array}$ & 38 & 3.2 & 3.2 & 27.7 \\
\hline Shock Push - Lack of it & 11 & .9 & .9 & 28.6 \\
\hline $\begin{array}{l}\text { Shock Pull - New } \\
\text { employment opportunity }\end{array}$ & 110 & 9.3 & 9.3 & 37.9 \\
\hline $\begin{array}{l}\text { Shock Pull - } \\
\text { Pension/retirement/career } \\
\text { change }\end{array}$ & 79 & 6.7 & 6.7 & 44.6 \\
\hline Shock Pull - Family needs & 46 & 3.9 & 3.9 & 48.5 \\
\hline Shock Pull - Education & 14 & 1.2 & 1.2 & 49.7 \\
\hline $\begin{array}{l}\text { Shock Pull - Personal } \\
\text { circumstances }\end{array}$ & 3 & 3 & .3 & 50.0 \\
\hline $\begin{array}{l}\text { Non Shock - Pull - } \\
\text { Pension/retirement/end of } \\
\text { contract }\end{array}$ & 9 & .8 & .8 & 50.7 \\
\hline $\begin{array}{l}\text { Non Shock - Push - } \\
\text { Dissatisfaction - leadership }\end{array}$ & 82 & 7.0 & 7.0 & 57.7 \\
\hline $\begin{array}{l}\text { Non Shock Push - } \\
\text { Operational tempo }\end{array}$ & 40 & 3.4 & 3.4 & 61.1 \\
\hline
\end{tabular}




\begin{tabular}{lcccc}
$\begin{array}{l}\text { Non Shock Push - } \\
\text { Pay/benefits }\end{array}$ & 21 & 1.8 & 1.8 & \\
$\begin{array}{l}\text { Non Shock Push - Career } \\
\text { management/raining }\end{array}$ & 66 & 5.6 & 5.6 & 68.4 \\
$\begin{array}{l}\text { issues/promotion } \\
\text { Non Shock Push - Lack of fit }\end{array}$ & 47 & 4.0 & 4.0 & 72.4 \\
$\begin{array}{l}\text { Non Shock Push - } \\
\text { Dissatisfaction - working }\end{array}$ & 101 & 8.6 & 8.6 & 81.0 \\
$\begin{array}{l}\text { environment } \\
\text { Non Shock Push - Met } \\
\text { expectations }\end{array}$ & 16 & 1.4 & 1.4 & 82.4 \\
$\begin{array}{l}\text { Non Shock Push - } \\
\text { Overworked/stressed }\end{array}$ & & & & 84.6 \\
$\begin{array}{l}\text { Non Shock Pull - Work life } \\
\text { balance }\end{array}$ & 27 & 2.3 & 2.3 & 85.8 \\
$\begin{array}{l}\text { Non Shock Pull - Career/life } \\
\text { change }\end{array}$ & 13 & 1.1 & 1.1 & 91.9 \\
$\begin{array}{l}\text { Non Shock Pull - Location } \\
\text { stability }\end{array}$ & 72 & 6.1 & 6.1 & \\
$\begin{array}{l}\text { Non Shock - Pull - Family } \\
\text { needs }\end{array}$ & 20 & 1.7 & 1.7 & 93.6 \\
\begin{tabular}{l} 
Total \\
\hline
\end{tabular} & 76 & 6.4 & 6.4 & 100.0 \\
\hline
\end{tabular}


Appendix C: Responses to "What finally made you decide to leave the CF?"Complete set of themes identified

Cumulative

Frequency Percent Valid Percent Percent

\begin{tabular}{|c|c|c|c|c|}
\hline Shock - Push - Posting & 115 & 9.8 & 9.8 & 9.8 \\
\hline $\begin{array}{l}\text { Shock - Push - Operational } \\
\text { tempo/Deployment }\end{array}$ & 20 & 1.7 & 1.7 & 11.5 \\
\hline $\begin{array}{l}\text { Shock - Push - Career } \\
\text { management/Promotion/Trai } \\
\text { ning issues }\end{array}$ & 59 & 5.0 & 5.0 & 16.5 \\
\hline $\begin{array}{l}\text { Shock - Push - } \\
\text { Health/Fitness issues }\end{array}$ & 24 & 2.0 & 2.0 & 18.5 \\
\hline Shock - Push - Lack of fit & 19 & 1.6 & 1.6 & 20.1 \\
\hline Shock - Push - Other & 8 & .7 & .7 & 20.8 \\
\hline $\begin{array}{l}\text { Shock - Pull - } \\
\text { JobMork/Business } \\
\text { opportunity }\end{array}$ & 198 & 16.8 & 16.8 & 37.6 \\
\hline $\begin{array}{l}\text { Shock - Pull - } \\
\text { Pension/Retirement/End of } \\
\text { contract }\end{array}$ & 74 & 6.3 & 6.3 & 43.9 \\
\hline Shock - Pull - Family needs & 41 & 3.5 & 3.5 & 47.3 \\
\hline Shock - Pull - Education & 17 & 1.4 & 1.4 & 48.8 \\
\hline $\begin{array}{l}\text { Shock - Pull - Personal } \\
\text { circumstances }\end{array}$ & 11 & .9 & .9 & 49.7 \\
\hline $\begin{array}{l}\text { Non Shock - Pull - Job } \\
\text { opportunity }\end{array}$ & 107 & 9.1 & 9.1 & 58.8 \\
\hline Non Shock - Pull - & 48 & 4.1 & 4.1 & 62.8 \\
\hline
\end{tabular}




\begin{tabular}{|c|c|c|c|c|}
\hline $\begin{array}{l}\text { Non Shock - Push - } \\
\text { Dissatisfaction - leadership }\end{array}$ & 49 & 4.2 & 4.2 & 67.0 \\
\hline $\begin{array}{l}\text { Non Shock - Push - } \\
\text { Operational } \\
\text { tempo/Deployments }\end{array}$ & 39 & 3.3 & 3.3 & 70.3 \\
\hline $\begin{array}{l}\text { Non Shock - Push - } \\
\text { Pay/Benefits }\end{array}$ & 11 & .9 & .9 & 71.2 \\
\hline $\begin{array}{l}\text { Non Shock - Push - Career } \\
\text { Management/Promotion/train } \\
\text { ing issues }\end{array}$ & 71 & 6.0 & 6.0 & 77.3 \\
\hline $\begin{array}{l}\text { Non Shock - Push - Lack of } \\
\text { fit }\end{array}$ & 33 & 2.8 & 2.8 & 80.1 \\
\hline $\begin{array}{l}\text { Non Shock - Push - } \\
\text { Dissatisfaction - working } \\
\text { conditions }\end{array}$ & 68 & 5.8 & 5.8 & 85.8 \\
\hline $\begin{array}{l}\text { Non Shock - Push - } \\
\text { Overworked/Stressed }\end{array}$ & 16 & 1.4 & 1.4 & 87.2 \\
\hline $\begin{array}{l}\text { Non Shock - Pull - } \\
\text { Career/Life change }\end{array}$ & 26 & 2.2 & 2.2 & 89.4 \\
\hline $\begin{array}{l}\text { Non Shock - Pull - Location } \\
\text { stability }\end{array}$ & 10 & .8 & .8 & 90.2 \\
\hline $\begin{array}{l}\text { Non Shock - Pull - Family } \\
\text { needs }\end{array}$ & 63 & 5.3 & 5.3 & 95.6 \\
\hline Non Shock - Push - Posting & 27 & 2.3 & 2.3 & 97.9 \\
\hline $\begin{array}{l}\text { Non Shock - Push - } \\
\text { Health/Fitness issues }\end{array}$ & 16 & 1.4 & 1.4 & 99.2 \\
\hline Non Shock - Pull - Education & 9 & .8 & .8 & 100.0 \\
\hline Total & 1179 & 100.0 & 100.0 & \\
\hline
\end{tabular}

